DAVE SIROIS-GAGNON

\title{
ASSOCIATION ENTRE L'OBÉSITÉ ET DES POLYMORPHISMES COMMUNS DANS LE RÉCEPTEUR DE LA FRACTALKINE (CX3CR1)
}

\author{
Mémoire présenté \\ à la Faculté des études supérieures de l'Université Laval \\ comme exigence partielle du programme de mâ̂trise en médecine expérimentale \\ offert à l'Université du Québec à Chicoutimi \\ en vertu d'un protocole d'entente avec l'Université Laval \\ pour l'obtention du grade de maître ès sciences (M.Sc.)

\section{FACULTÉ DE MÉDECINE UNIVERSITÉ LAVAL QUÉBEC} \\ et \\ DÉPARTEMENT DES SCIENCES HUMAINES \\ UNIVERSITÉ DU QUÉBEC À CHICOUTIMI \\ SAGUENAY
}

2011

(C) Dave Sirois-Gagnon, 2011 


\section{RÉSUMÉ}

Selon les données de l'Organisation mondiale de la Santé (OMS), l'obésité a atteint des proportions pandémiques dans le monde entier, avec plus d'un milliard d'adultes qui présentent un surpoids (indice de masse corporelle (IMC) $>25 \mathrm{~kg} / \mathrm{m}^{2}$ ) dans le monde entier, et au moins 300 millions cliniquement obèses (IMC $\geq 30 \mathrm{~kg} / \mathrm{m}^{2}$ ). L'obésité est un trait complexe qui ne suit pas un mode de transmission mendélienne classique, ce qui implique qu'elle est influencée par l'interaction entre les gènes, l'environnement et le mode de vie. L'obésité est également reconnue pour être associée à une composante inflammatoire caractérisée par une production anormale de cytokines et l'activation de voies de signalisation inflammatoires dans le tissu adipeux. Le gène $C X 3 C R I$ code pour le récepteur de la fractalkine (CX3CR1) et possède deux polymorphismes nucléotidiques simples (Single Nucleotide Polymorphisms: SNPs), V249I et T280M, situés dans une région codante, et qui ont été associés à un risque moins élevé de présenter certaines maladies inflammatoires telles que les maladies coronariennes et l'asthme. Dans le but de déterminer si CX3CRI est associé à l'obésité, nous avons procédé au génotypage des polymorphismes V249I et T280M du gène CX3CRI chez des sujets ayant un IMC $\geq 30$ $\mathrm{kg} / \mathrm{m}^{2}$ et des témoins non obèses avec un IMC $<30 \mathrm{~kg} / \mathrm{m}^{2}$. Les analyses ont révélé que le génotype 280MM est associé à l'obésité $(\mathrm{p}=0,022)$. Pour les deux polymorphismes, et ce de manière indépendante, les femmes portant deux copies de l'allèle mineur avait un tour de taille qui était en moyenne significativement plus élevé que celles qui ne portent qu'une seule copie de l'allèle mineur ( $\mathrm{MM}>\mathrm{TM}, \mathrm{P}=0,031$; II $>\mathrm{VI}, \mathrm{P}=0,013)$, ou celles qui étaient homozygotes pour l'allèle majeur ( $M M>T T, p=0,005$; I $>V V, P=0,006$ ). Nous avons également observé un tour de taille en moyenne significativement supérieur chez les hommes portant une copie de l'allèle mineur par rapport à ceux qui étaient homozygotes pour l'allèle majeur pour le polymorphisme T280M (TM> TT, $\mathrm{P}=0,029)$. Cette étude suggère que CX3CRI constitue une cible potentielle d'investigation sur le rôle de l'inflammation dans l'expression de phénotypes de l'obésité. 


\begin{abstract}
AVANT-PROPOS
Ce mémoire comprend un article scientifique. Je tiens à remercier les co-auteurs de l'article et à souligner leur participation à cet ouvrage.

Je remercie la Docteure Catherine Laprise de m'avoir permis d'approfondir mes connaissances dans un domaine aussi passionnant que la génétique.

Il est important de mentionner l'apport d'Annie Chamberland non seulement à titre de coauteur du manuscrit, mais également pour toutes les informations partagées et les connaissances qu'elle m'a transmises.
\end{abstract}

Je tiens à remercier tous les enseignants qui m'ont formé au cours de ma maitrise. Un merci spécial va à l'une d'entre eux, la Docteure Diane Brisson, qui m'a enseigné les biostatistiques et qui a contribué à la rédaction du manuscrit.

Je remercie particulièrement le Docteur Daniel Gaudet de nous avoir accordé la permission d'utiliser la cohorte dont il est le responsable et pour sa participation indispensable à la rédaction du manuscrit.

Merci aux participants de cette étude.

Je salue les gens que j'ai côtoyés lors de mon passage dans le laboratoire Gépromic.

Chers parents, je profite ici de l'occasion pour vous remercier, vous qui m'avez tant donné. 


\section{TABLE DES MATIÈRES}

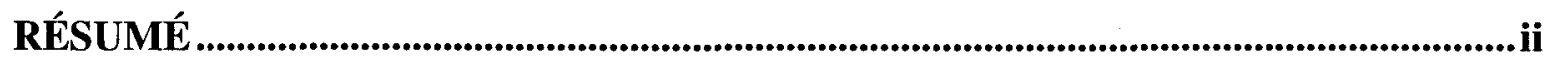

AVANT-PROPOS ...................................................................................................................ii

TABLE DES MATIÈRES .....................................................................................................iv

LISTE DESTABLEAUX ............................................................................................ vi

LISTE DES FIGURES...........................................................................................................vii

LISTE DES ABBRÉVIATIONS ...................................................................................viii

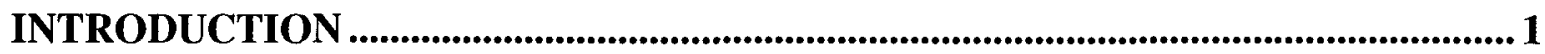

CHAPITRE 1 TRAITEMENT PHARMACOLOGIQUE DE L'OBÉSITÉ .................3

CHAPITRE 2 GÉNÉTIQUE DE L'OBÉSITÉ........................................................6

2.1. HÉRITABILITÉ DE L'OBÉSITÉ ...............................................................6

2.2 ÉPIGÉNÉTIQUE ET OBÉSITÉ .................................................................6

2.3 L'APPROCHE PAR GÈNE CANDIDAT............................................................. 7

2.4 LES ÉTUDES D'ASSOCIATION PANGÉNOMIQUES ....................................... 8

2.5 ÉTUDE D'EXPRESSION GÉNIQUE ET TRANSCRIPTOGÉNOMIQUE .....9

CHAPITRE 3 LE TISSU ADIPEUX : UN ORGANE ENDOCRINE .......................... 11

3.1 CHANGEMENTS DANS LES ADIPOCYTES.................................................12

3.2 INFLAMMATION DANS LE TISSU ADIPEUX ................................................. 12

3.2.1 CHANGEMENTS DYNAMIQUES DANS LA COMPOSITION DU TISSU

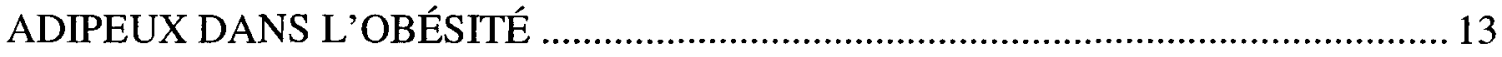

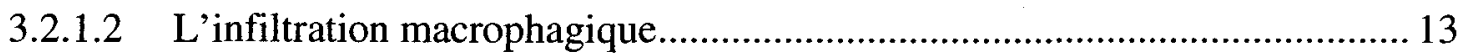

3.2.1.3 Macrophage : états de polarisation M1 et M2 ........................................... 13

3.2.1.4 Activation des cellules endothéliales.......................................................... 14

3.2.2 LES CYTOKINES PRO-INFLAMMATOIRES ET LES CHIMIOKINES

SÉCRÉTÉES DANS LE TISSU ADIPEUX.............................................................. 16

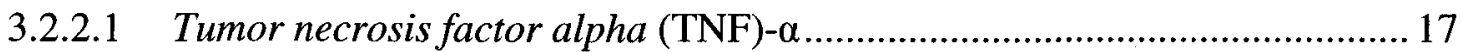

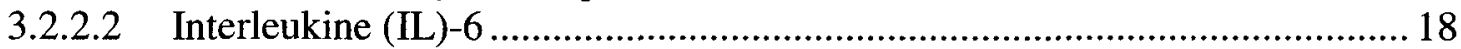

3.2.2.3 Monocyte chemoattractant protein (MCP)-1 …........................................ 19 
CHAPITRE 4 LE RÉCEPTEUR (CX3CR1) ET SES LIGANDS .......................... 22

4.1 LES CHIMIOKINES .................................................................................. 22

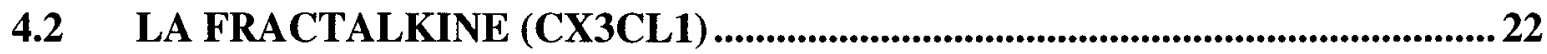

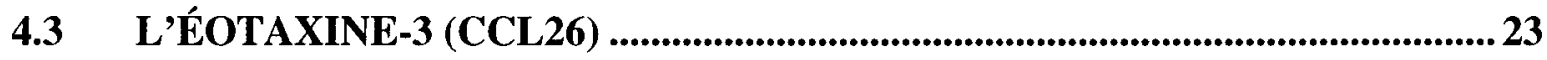

4.4 LE RÉCEPTEUR DE LA FRACTALKINE (CX3CR1) ................................. 23

4.5 LE COMPLEXE CX3CL1/CX3CR1 ............................................................... 25

CHAPITRE 5 ASSOCIATION ENTRE L'OBÉSITÉ ET DES

POLYMORPHISMES COMMUNS DANS LE RÉCEPTEUR DE LA

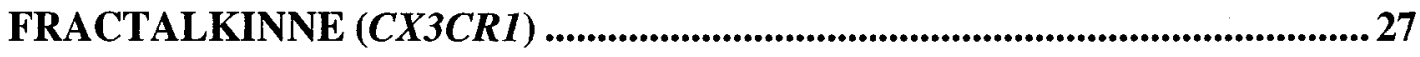

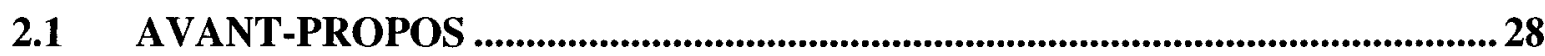

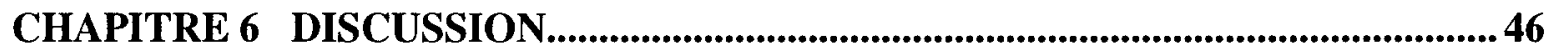

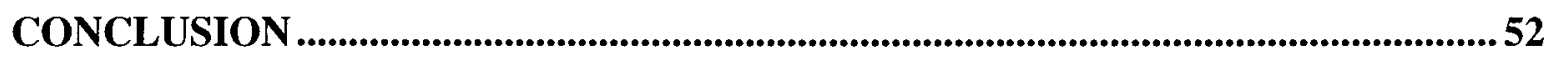

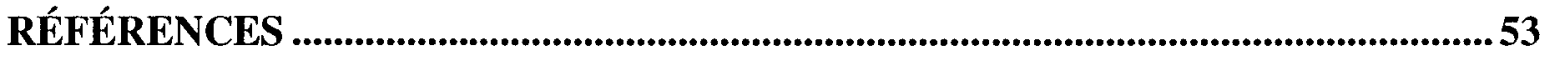




\section{LISTE DESTABLEAUX}

Tableau 1: Adipokines, chimiokines et protéines vasculaires produites dans le tissu adipeux et impliquées dans le métabolisme, l'homéostasie énergétique et les réactions

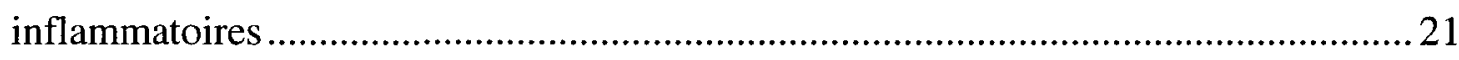

Tableau 2: TABLE 1- Clinical characteristics of the subjects studied ................................ 42

Tableau 3 : TABLE 2- Genotype odds ratios associated with obesity for the V249I and T280M variants of the CX3CR1 gene.................................................................... 43

Tableau 4 : TABLE 3- Gender-specific one-way analysis of variance of mean BMI and waist circumference differences between genotypes of the V249I and T280M polymorphisms of the $C X 3 C R 1$ gene ........................................................................ 44 


\section{LISTE DES FIGURES}

Figure 1 : Schéma représentant les deux types d'obésité ; androïde et gynoïde.................. 2

Figure 2 : Inflammation dans le tissu adipeux .................................................... 15 


\section{LISTE DES ABBRÉVIATIONS}

ADIPOQ Adiponectine

ALA Acide $\alpha$-linolénique

AIDS Acquired immune deficiency syndrome

AHA American heart association

$B D N F \quad$ Brain-derived neurotrophic factor

BMI Body mass index

CAD Coronary artery disease

CAM Molécules d'adhérence cellulaire (Cell adhesion molecules)

CB1 Récepteurs endocannabinoïdes

CCL2 Chemokine (CC motif) Ligand 2

CRP Protéine C-réactive ( $C$ reactive protein)

CTNNBL1 Catenin, beta-like 1

C Sous-famille de chimiokines : cystéine

CC Sous-famille de chimiokines : cystéine-cystéine

CXC Sous-famille de chimiokines : cystéine-acide aminé $x$-cystéine

CX3C Sous-famille de chimiokines : cystéine-3 acides aminés $x$-cystéine

CX3CL1 CX3C ligand 1

CX3CRI Récepteur de la fractalkine

DHA Acide docosahexanoïque

EPA Acide eicosapentaénoïque

ESCC Enquête sur la santé dans les collectivités canadiennes

E-selectin Sélectine-E (Endothelial-leukocyte adhesion molecule)

FTO Fat mass and obesity associated

FKN Fractalkine

GWAS Genome Wide Association Study

HDL-C High-density lipoprotein cholesterol

HRM High Resolution Melt 
HWE Hardy-Weinberg equilibrium

ICAM Molécules d'adhésion intercellulaire (Intercellular adhesion molecule)

IL Interleukine

IMC Indice de masse corporelle

Jak -Stat Janus kinase/signal transducers and activators of transcription

JNK C-Jun NH2-terminal kinase

KO Knock-out

LDL-C Low-density lipoprotein cholesterol

MCA Melting curve analysis

MC4R Melanocortin receptor 4

MCP Protéine chimiotactique des monocytes (Monocyte chemoattractant protein)

m-FKN Fractalkine associée à la membrane

MIF Migration inhibitory factor

MS Metabolic syndrome

NF-kB Nuclear factor-kappa binding

NGEF Neuronal guanine nucleotide exchange factor

NK Natural killer cells

NO Oxyde nitrique (Nitric Oxyde)

OGTT Oral glucose tolerance test

OMS Organisation Mondiale de la Santé

OPN Ostéopontine

OR Odds ratio

PAI Plasminogen activator inhibitor

PCR Polymerase chain reaction

PCSK1 Prohormone convertase 1/3

PTER Phosphotriesterase related

RGS6 Regulator of G-protein signaling 6

ROS Reactive oxygen species

s-FKN Fractalkine soluble 


$\begin{array}{ll}\text { SLSJ } & \text { Saguenay-Lac-Saint-Jean } \\ \text { SNPS } & \text { Single nucleotide polymorphisms } \\ \text { SPSS } & \text { Statistical package for the social sciences } \\ \text { TNF } & \text { Facteur nécrosant des tumeurs (Tumor necrosis factor) } \\ \text { TGF } \beta & \text { Tumor growth factor beta } \\ \text { TNFR1 } & \text { TNF- } \alpha \text { receptor } 1 \\ \text { VCAM } & \text { Molécule d'adhésion cellulaire vasculaire (Vascular cell adhesion molecule) } \\ \text { VLDL } & \text { Very low-density lipoprotein } \\ \text { WHO } & \text { World Health Organization } \\ \text { ZFP36 } & \text { Zinc finger protein } 36\end{array}$




\section{INTRODUCTION}

L'obésité est très répandue dans les pays industrialisés et dans les pays en développement du monde entier ${ }^{1}$. Selon les estimations de l'Enquête sur la santé dans les collectivités canadiennes (ESCC), 59,1\% des Canadiens âgés de 18 ans et plus ont un surpoids et $23,1 \%$ d'entre eux sont obèses ${ }^{2}$.

Le phénotype obèse est d'origine multifactorielle. Des facteurs psychoaffectifs et environnementaux (familiaux et sociaux), ainsi que des facteurs génétiques et épigénétiques sont impliqués, ces facteurs interagissant entre eux ${ }^{3,4}$. Il est important de noter que l'obésité augmente le risque de mort prématurée puisqu'elle est un facteur de risque associé à des maladies chroniques telles que le diabète de type 2, la dyslipidémie, l'athérosclérose, l'hypertension artérielle, les maladies cardiovasculaires, les accidents vasculaires cérébraux et certaines formes de cancer ${ }^{5,6}$. En plus du déséquilibre métabolique reconnu dans cette pathologie, l'obésité influence d'autres fonctions physiologiques importantes. À titre d'exemple, le tissu adipeux blanc est caractérisé par une sécrétion active de molécules impliquées dans la réponse immunitaire ${ }^{7}$.

L'obésité est généralement évaluée cliniquement par la mesure de l'indice de masse corporelle (IMC) qui correspond au rapport du poids en kilogramme sur le carré de la taille en mètre $\left(\mathrm{kg} / \mathrm{m}^{2}\right)$. L'IMC est divisé en plusieurs classes et constitue un outil standardisé de recherche utilisé dans la plupart des études sur l'obésité. Ces classes définissent les individus avec un poids santé $\left(20-24,9 \mathrm{~kg} / \mathrm{m}^{2}\right)$, une surcharge pondérale $\left(25-29,9 \mathrm{~kg} / \mathrm{m}^{2}\right)$ et les individus obèses $\left(\geq 30 \mathrm{~kg} / \mathrm{m}^{2}\right)$, selon les standards acceptés et recommandés par l'Organisation Mondiale de la Santé (OMS) chez les personnes âgées de plus de 18 ans ${ }^{8}$. 
L'obésité se divise en deux types distincts avec leurs conséquences métaboliques propres (Figure 1). L'obésité androïde (ou centrale) est caractérisée par une augmentation du tissu adipeux dans la région abdomino-tronculaire. L'obésité gynoïde désigne l'augmentation du tissu adipeux dans la région fémoro-glutéale. Depuis plus de soixante ans, il est reconnu que la distribution du gras corporel est plus importante que la mesure du gras corporel total afin d'estimer le risque de développer des maladies cardiovasculaires et d'autres troubles métaboliques ${ }^{9}$. Il est bien établi que l'obésité andrö̈de est associée à une morbidité plus élevée que l'obésité gynoïde ${ }^{10}$. L'obésité androïde est un facteur de risque de diabète de type II, d'hypertension artérielle, de dyslipidémies et de maladies cardiovasculaires, alors que l'obésité gynö̈de ne semble pas avoir de conséquences métaboliques importantes ${ }^{11,12}$. Il est établi que le tour de taille, par l'estimation de graisse viscérale, demeure un important instrument de mesure afin de prédire le risque de diabète de type 2 et de maladies cardiovasculaires ${ }^{13,14}$. Par ailleurs, il a également été démontré que la graisse sous-cutanée abdominale, estimée à l'aide de l'IMC, est un facteur prédictif indépendant de la résistance à l'insuline ${ }^{15,16}$. Janssen et al. ${ }^{17}$ ont démontré que l'IMC et le tour de taille contribuent indépendamment à l'estimation du dépôt de graisse non abdominale, sous-cutanée abdominale et viscérale chez les hommes et les femmes caucasiens. Ces observations renforcent l'importance de l'utilisation de l'IMC et du tour de taille.

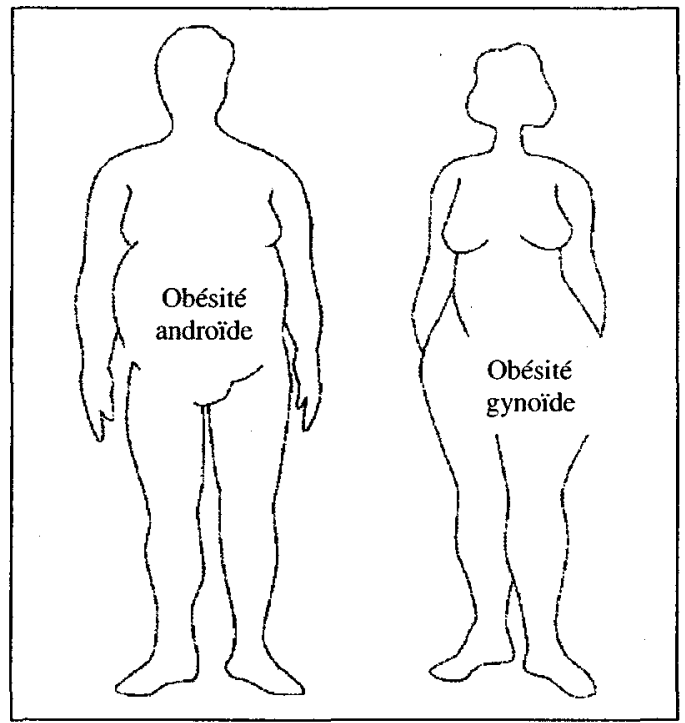

Figure 1 : Schéma représentant les deux types d'obésité ; androïde et gynoïde. Modifié de Carr, $2003^{18}$. 


\section{CHAPITRE 1}

\section{TRAITEMENT PHARMACOLOGIQUE DE L'OBÉSITÉ}

La prescription de médicaments afin de traiter l'obésité peut permettre de réduire la masse de tissu adipeux chez les personnes obèses et par le fait même l'inflammation et les composantes souvent associées à l'obésité et caractéristiques du syndrome métabolique telles que l'insulinorésistance et l'hypertension. Les médicaments potentiels pour le traitement de l'obésité faisant l'objet de recherche peuvent être classés dans quatre groupes: 1) ceux qui provoque une réduction de l'appétit en agissant sur le système nerveux central ; 2) ceux qui accélère le métabolisme ; 3) ceux qui agissent sur le tractus gastro-intestinal ; 4) ceux qui agissent à la fois sur l'obésité et sur les autres phénotypes reliés au syndrome métabolique ${ }^{19}$.

Au Canada, l'Orlistat (Xenical) et la Sibutramine (Meridia, Reductil) sont deux médicaments prescrits pour contrer l'obésité ${ }^{20}$. Ces deux médicaments ont des effets différents sur la dyslipidémie associée à l'obésité androïde. L'Orlistat est un inhibiteur de la lipase gastrointestinale qui réduit l'absorption des graisses. Chez les sujets ayant reçu le médicament, une perte de poids est observée avec une amélioration du cholestérol total et du low-density lipoprotein cholesterol (LDL-C) par rapport à ceux ayant reçu le placebo, mais sans effet notable sur les concentrations plasmatiques de triglycérides et de high-

density lipoprotein cholesterol (HDL-C) ${ }^{21,22}$. La Sibutramine est un médicament agissant sur le système nerveux central et qui inhibe la recapture de la sérotonine et de la norépinéphrine. La Sibutramine peut avoir un effet négatif sur la pression artérielle et la fréquence cardiaque, ce qui limite ainsi son utilisation chez des patients présentant des caractéristiques physiques et métaboliques associées au syndrome métabolique. La perte de 
poids induite par la Sibutramine s'accompagne d'une amélioration des concentrations plasmatiques de triglycérides et de HDL-C qui semble être directement dépendante de la perte pondérale ${ }^{23}$.

Le Rimonabant (Acomplia) est un bloqueur des récepteurs endocannabinoïdes CB1. Le Rimonabant est un antagoniste sélectif des récepteurs $\mathrm{CB} 1$ qui induit une diminution des apports alimentaires. Un programme de développement a été instauré pour ce médicament afin de traiter les patients obèses présentant des facteurs de risque associés (dyslipidémie, insulinorésistance) ${ }^{24-27}$.

La Metformine (Glucophage), utilisée afin de réduire la glycémie dans le traitement du diabète de type 2 , peut amener une réduction du poids chez les obèses ${ }^{28}$.

Cependant, la prise de médicaments peut amener des effets secondaires ${ }^{19}$. Certains effets peuvent être minimes et avoir peu d'influence sur la commercialisation du médicament, alors que d'autres effets peuvent mener à l'interdiction de vente du produit. De fait, la prescription du Rimonabant est interdite aux États-Unis étant donné le risque de troubles psychiatriques pouvant mener au suicide ${ }^{29}$.

Le développement de nouvelles voies thérapeutiques avec des effets secondaires à conséquences moins dommageables est primordial. La modification de l'expression de gènes codant des adipokines et de la libération de celles-ci dans la circulation pourrait constituer des avenues thérapeutiques intéressantes. D'autres stratégies potentiellement envisageables comprennent le ciblage des mécanismes impliqués dans le recrutement des macrophages circulants ainsi que la compréhension des mécanismes moléculaires responsables de la polarisation des macrophages. Enfin, la compréhension des voies de signalisation dans d'autres tissus ciblés tels que le cerveau, le muscle squelettique et le foie qui contrôlent le métabolisme des adipokines pourrait aussi révéler de nouvelles pistes pour le développement de thérapies pour l'obésité et les phénotypes qui lui sont liées. 
L'identification d'autres récepteurs impliqués dans les mécanismes associés à l'inflammation dans le tissu adipeux obèse pourrait également permettre de constituer une nouvelle liste de candidats comme cible thérapeutique potentielle.

Ainsi, l'étude des sciences dites «omiques» (génomique, protéomique, transcriptomique, métabolomique) permettra de bien définir la nature moléculaire de cette pathologie et l'identification de nouvelles cibles pour le développement de thérapies personnalisées. 


\section{CHAPITRE 2}

\section{GÉNÉTIQUE DE L'OBÉSITÉ}

\subsection{HÉRITABILITÉ DE L'OBÉSITÉ}

Des études chez les couples de jumeaux où l'on compare le taux de concordance pour un caractère entre les couples de jumeaux monozygotes et dizygotes, des études d'adoptions où l'on compare l'enfant adopté à l'enfant biologique afin de déterminer l'influence de l'environnement et celle de la génétique, et les études familiales indiquent que jusqu'à $80 \%$ de la variance de l'indice de masse corporelle (IMC) est attribuable à des

facteurs génétiques ${ }^{30-32}$. En effet, il a été estimé que le risque relatif d'obésité chez les frères et sours est de 3 à 7 fois plus élevé ${ }^{33}$, et que le taux de concordance de l'obésité est plus élevé chez les jumeaux monozygotes que chez les jumeaux dizygotes, respectivement 0,74 et $0,32^{32}$. De plus, le poids chez les adoptés est souvent plus proches de leurs parents biologiques que leurs parents adoptifs ${ }^{30}$. Ces études ainsi que plusieurs méta-analyses intégrant les données sur les couples de jumeaux, les enfants adoptés et les études familiales ont estimé que l'héritabilité de l'IMC ou la graisse corporelle est de $25 \%$ à $40 \%$ ${ }^{30,34-36}$. Ces études soutiennent le rôle des gènes dans la pathogenèse de l'obésité humaine.

\section{2 ÉPIGÉNÉTIQUE ET OBÉSITÉ}

De manière générale, on reconnaît l'épigénétique comme l'ensemble des changements d'expression génique ne modifiant pas la séquence d'ADN. La modification de la structure de l'ADN et des protéines associées, comme par exemple son 
hyperméthylation ou le remodelage de la chromatine par la modification des histones (méthylation, acétylation, phosphorylation) sont en cause ${ }^{4}$.

Certains gènes impliqués dans le développement de l'obésité seraient contrôlés par des mécanismes de régulation épigénétique. Ainsi, la diète de la mère influencerait la croissance foetale et la prédisposition à développer un syndrome métabolique à l'âge adulte 37. Des facteurs épigénétiques interviennent dans l'environnement nutritionnel fotoplacentaire et postnatal, jouant un rôle programmateur sur le poids. À l'âge adulte, la diète aurait un effet sur l'expression de certains gènes par la méthylation de l'ADN ${ }^{38}$. Les mécanismes épigénétiques influant le développement de l'obésité sous-entendent l'altération de l'expression de gènes impliqués entre autres dans la régulation de fonctions physiologiques comme le métabolisme du glucose, l'adipogenèse et l'inflammation. De nombreuses modifications suite à une régulation épigénétique peuvent survenir durant l'ovogénèse et le développement embryonnaire ${ }^{39,40}$. De plus, certains acides gras retrouvés dans l'alimentation peuvent diminuer l'inflammation. C'est le cas des acides gras omega-3, comme l'acide $\alpha$-linolénique (ALA) et ses dérivés l'acide eicosapentaénoïque (EPA) et l'acide docosahexanoïque (DHA). Ces acides gras agissent sur les récepteurs du tumor necrosis factor et diminuent les concentrations de l'interleukine (IL)-6 et de la Protéine Créactive ( $C$ reactive protein : $\mathrm{CRP})^{41}$. Le rôle de ces acides gras sur le développement du cerveau et de la rétine est également reconnu ${ }^{42}$.

\subsection{L'APPROCHE PAR GÈNE CANDIDAT}

Les études de gènes candidats sont basées sur des hypothèses reliées à la compréhension actuelle de la biologie et de la physiopathologie qui sous-tend la susceptibilité de développer la maladie ${ }^{43}$. Dans les études d'association concernant l'obésité, les gènes ou les variants génétiques sont sélectionnés comme candidats potentiels de la maladie s'ils ont un rôle connu ou supposé dans le métabolisme ou s'ils sont situés 
dans une région du génome liée à l'obésité dans les études de liaison. L'accent est mis sur les variants non synonymes et les régions de régulation 5' et 3' UTR en raison de leurs potentielles implications fonctionnelles.

Depuis les premières études de gènes candidats pour les traits reliées à l'obésité, il y a 15 ans, le nombre de gènes de susceptibilité proposés pour le développement de l'obésité n'a cessé de croître. La dernière mise à jour de la Human Obesity Gene Map rapportait 127 gènes candidats pour lesquels au moins une étude a rapporté une association positive avec des traits liés à l'obésité ${ }^{44}$. Des associations ont été observées pour les variants non synonymes dans plusieurs gènes (par exemple melanocortin receptor $4(M C 4 R)^{45}$, prohormone convertase $1 / 3(P C S K I)^{46}$, brain-derived neurotrophic factor $\left.(B D N F)^{47}\right)$. Ces trois gènes constituent des cibles thérapeutiques. Plusieurs mutations du gène du $M C 4 R$ ont été identifiées et associées à l'apparition d'une obésité précoce sévère chez l'homme ${ }^{48}$. Des essais pharmacologiques ont démontré que le MC4R est impliqué dans la régulation de la prise alimentaire ${ }^{49,50}$. Le gène $P C S K 1$ code pour une enzyme qui est responsable de la conversion de prohormones en hormones impliquées dans la régulation du métabolisme énergétique. Les individus avec des mutations rares dans le gène $P C S K I$ sont caractérisés par une obésité infantile extrême ${ }^{51,52}$. Le BDNF est une protéine qui influence le comportement alimentaire et la régulation du poids corporel ${ }^{53,54}$.

\subsection{LES ÉTUDES D’ASSOCIATION PANGÉNOMIQUES}

Les avancées récentes en matière de technologie performante ont rendu possible les études d'association sur le génome entier et l'identification de gènes impliqués dans le développement de maladies communes (traits complexes).

Une étude d'association pangénomique (Genome Wide Association Study: GWAS) sur des traits liés à l'obésité a démontré qu'un polymorphisme (rs9930506) du gène fat mass 
and obesity associated (FTO) sur le chromosome 16 est fortement associé avec l'IMC, le tour de hanche, et le poids corporel ${ }^{55}$. Les variants du gène FTO sont des facteurs de susceptibilité prédisposant au développement de l'obésité dans différentes populations ${ }^{56,57}$. Une autre étude d'association pangénomique chez des Hispano-Américains suggèrent l'implication de deux gènes candidats dans le développement de l'obésité. Le gène regulator of G-protein signaling 6 (RGS6) aurait une influence sur la distribution du tissu adipeux, alors que le gène neuronal guanine nucleotide exchange factor (NGEF) influencerait la quantité du tissu adipeux sous-cutané ainsi que viscéral ${ }^{58}$. D'autres déterminants génétiques de l'obésité ont été identifiés par les études d'association pangénomiques ${ }^{59-63}$.

\section{5 ÉTUDE D'EXPRESSION GÉNIQUE ET TRANSCRIPTOGÉNOMIQUE}

L'étude de l'expression génique consiste à identifier, caractériser et quantifier le transcriptome ou les séquences d'ADN transcrites en ARN messagers afin d'identifier, dans un tissu et dans un état précis, le taux d'expression des gènes dont elles sont codées. Cette stratégie peut être employée afin d'investiguer les différences d'expression génique entre plusieurs groupes différents.

La combinaison de deux approches de recherche permet parfois de trouver des gènes candidats potentiels qui pourraient influencer le développement d'une maladie ou d'un trait complexe. En effet, la transcriptogénomique est une stratégie qui intègre la génomique et la transcriptomique ${ }^{64}$. Une récente étude dans laquelle les chercheurs ont employé la transcriptogénomique a permis de révéler un nouveau gène candidat dans l'obésité reliée au syndrome métabolique ${ }^{65}$. Le Zinc finger protein 36 (ZFP36), qui est impliqué dans la régulation du Facteur nécrosant des tumeurs (Tumor necrosis factor (TNF))- $\alpha$ et situé sur le bras long du chromosome 19, une région liée au syndrome métabolique, a démontré une différence d'expression significative, soit 4,2 à 4,8 fois plus 
élevée, chez les sujets non atteints en comparaison avec ceux atteints du syndrome métabolique ${ }^{65}$. 


\section{CHAPITRE 3}

\section{LE TISSU ADIPEUX : UN ORGANE ENDOCRINE}

Le tissu adipeux sécrète un certain nombre de peptides ou de protéines bioactives, collectivement nommées «adipokines», qui est dérivé du terme «adipocytokines». Elles jouent un rôle central dans l'homéostasie énergétique et vasculaire, ainsi que dans l'immunité, et sont fondamentales dans la pathogénèse du syndrome métabolique ${ }^{66}$. Au milieu des années 1990, la description d'une expression accrue et de la sécrétion du TNF- $\alpha$ par le tissu adipeux de rongeurs obèses a permis de relier l'inflammation à l'obésité et à la résistance à l'insuline ${ }^{67}$. Un an plus tard, avec la découverte de la leptine, une adipokine sécrétée spécifiquement par les adipocytes et qui agit comme une hormone pour contrôler l'équilibre énergétique corporel, le tissu adipeux a effectivement été reconnu comme un organe endocrine ${ }^{68}$. Bien que la découverte de la leptine ait été déterminante dans l'évolution de notre compréhension du tissu adipeux, ce n'est pas la première protéine sécrétée par les adipocytes à être identifiée; car au milieu des années 1980, il a été démontré que l'adipsine est sécrétée par les cellules adipeuses ${ }^{69}$. Les adipokines englobent un large éventail de fonctions physiologiques et métaboliques, y compris l'appétit et l'équilibre énergétique, la sensibilité à l'insuline, l'hémostase vasculaire, la régulation de la

pression sanguine, le métabolisme des lipides, l'angiogenèse et l'inflammation ${ }^{70-74}$. Un certain nombre d'adipokines sont spécifiquement liées à l'immunité et à l'inflammation, et la réponse inflammatoire observée dans le tissu adipeux chez les obèses a suscité un intérêt 
particulier en ce qui concerne le développement des maladies associées au phénotype obèse $70,73,75,76$

\subsection{CHANGEMENTS DANS LES ADIPOCYTES}

Le tissu adipeux est composé de multiples compartiments d'emmagasinage des graisses répartis dans des dépôts sous-cutanés et viscéraux ${ }^{77}$. Le tissu adipeux blanc est le principal site d'emmagasinage des graisses et joue un rôle important dans l'emmagasinage de l'excès d'énergie provenant des aliments sous la forme d'acides gras ${ }^{78}$. La plasticité du tissu adipeux est bien connue ${ }^{79}$. L'hypertrophie et l'hyperplasie des adipocytes observées dans l'obésité sont associées à une réduction du débit sanguin, ainsi qu'à une réduction de la capture du glucose et des acides gras, et une augmentation de la lipolyse ${ }^{80-82}$. La taille des adipocytes est liée à une dysrégulation de l'expression et de la sécrétion des adipokines chez l'homme ${ }^{83,84}$.

\subsection{INFLAMMATION DANS LE TISSU ADIPEUX}

Le développement de l'inflammation dans le tissu adipeux de sujets obèses est accompagné de phénomènes caractéristiques des différents types cellulaires (Voir Figure 2 pour une représentation de l'inflammation dans le tissu adipeux). 


\subsubsection{CHANGEMENTS DYNAMIQUES DANS LA COMPOSITION DU TISSU ADIPEUX DANS L'OBÉSITÉ}

Dans l'obésité humaine, le tissu adipeux se caractérise par une hypertrophie (augmentation de la taille) et une hyperplasie (augmentation du nombre) des adipocytes, une infiltration macrophagique, l'activation endothéliale et une fibrose des cellules ${ }^{85-88}$.

\subsubsection{L'infiltration macrophagique}

L'obésité est associée à une infiltration de macrophages, une observation qui a jeté une nouvelle lumière dans la compréhension de l'inflammation liée à l'obésité ${ }^{89,}{ }^{90}$. D'autres cellules inflammatoires, comme les lymphocytes $\mathrm{T}$, qui infiltrent également le tissu adipeux chez les obèses pourraient y contribuer ${ }^{91}$. Des études de transplantation de moelle osseuse ont démontré que les macrophages infiltrant sont essentiellement dérivés de la moelle osseuse ${ }^{89}$. Chez l'humain, l'infiltration macrophagique est corrélée à la fois à la taille des adipocytes et à l'IMC ${ }^{89}$ et cette infïltration est réduite après une perte de poids induite par chirurgie chez des sujets souffrant d'obésité morbide ${ }^{92}$. Il y a aussi une infiltration préférentielle des macrophages dans le gras viscéral comparativement au gras sous-cutané, un phénomène amplifié par l'obésité centrale ${ }^{88,93,94 .}$

\subsubsection{Macrophage : états de polarisation M1 et M2}

On distingue deux populations de macrophages résidents dans le tissu adipeux : une population présentant un phénotype pro-inflammatoire (M1) et l'autre un phénotype antiinflammatoire (M2) ${ }^{95}$. Dans un modèle murin, il a été rapporté que, dans le tissu adipeux, le nombre de macrophages M2 diminue au profit des M1 suite à un gain de poids ${ }^{96}$. Les monocytes qui infiltrent le tissu adipeux de sujets humains obèses se retrouvent autour des adipocytes formant ainsi une disposition en forme de couronne. Les macrophages 
colocalisent également avec les adipocytes en sénescence, absorbent les gouttelettes lipidiques libérées après la nécrose des adipocytes et forment ensuite des cellules géantes plurinucléées qui désignent un stade inflammatoire avancé ${ }^{97}$.

\subsubsection{Activation des cellules endothéliales}

Dans l'inflammation, l'activation des cellules endothéliales résulte en l'activation de voies de signalisation intracellulaires conduisant à la production, de façon coordonnée et régulée, d'une série de molécules d'adhérence cellulaire (Cell adhesion molecules: CAM), ainsi que de chimiokines et de cytokines, qui guide les leucocytes dans les tissus sousjacents et stimulent leur activation complète ${ }^{98}$. Ceci mène ultimement à l'adhérence des monocytes sur les cellules endothéliales et engendre la diapédèse des monocytes à travers les jonctions cellulaires endothéliales et, par le fait même, l'infiltration dans le tissu adipeux ${ }^{98}$. Presque toutes les molécules d'adhésion sont présentes sous forme soluble dans le sang. Les concentrations de molécule d'adhésion intercellulaire (Intercellular adhesion molecule: ICAM)-1 soluble, de molécule d'adhésion cellulaire vasculaire (Vascular cell adhesion molecule: VCAM)-1, et de Sélectine-E (Endothelial-leukocyte adhesion molecule (E-selectin))-1 circulantes sélective des cellules endothéliales sont augmentées chez les adultes obèses et diminuent après une perte de poids ${ }^{99}$. Les cellules endothéliales peuvent être activées par des médiateurs de l'inflammation, tels que les chimiokines (Protéine chimiotactique des monocytes (Monocyte chemoattractant protein (MCP))-1), les cytokines (TNF- $\alpha$, Interleukine (IL)-6) et les adipokines (leptine, résistine), sécrétés par les macrophages et les adipocytes. Ainsi, l'incubation de cellules endothéliales avec des adipocytes matures provenant de tissu adipeux humain résulte en une régulation à la hausse de molécules d'adhésion cellulaire endothéliales et une diapédèse accrue des monocytes du sang ${ }^{100}$. L'administration d'anticorps anti-ICAM-1 à des souris obèses supprime l'adhérence des leucocytes aux cellules endothéliales et, améliore le fonctionnement des cellules endothéliales et le flux sanguin dans le tissu adipeux ${ }^{101}$. 
Chez les modèles animaux d'obésité génétique ou induite, l'expansion du tissu adipeux est associée à une angiogenèse active ${ }^{102,103}$. L'adipogenèse, ou la formation de cellules adipeuses, induit un état d'hypoxie pour ces adipocytes nouvellement formés, ce qui instaure la sécrétion de facteurs angiogéniques ${ }^{104}$. La corrélation entre la densité des adipocytes et la densité des capillaires sanguins témoigne du rôle de la néovascularisation dans le développement du tissu adipeux. L'administration d'un inhibiteur synthétique de l'angiogenèse dans un modèle murin d'obésité a non seulement diminué de façon sélective la masse adipeuse, mais a également amélioré la sensibilité à l'insuline ainsi que le profil lipidique ${ }^{102}$.

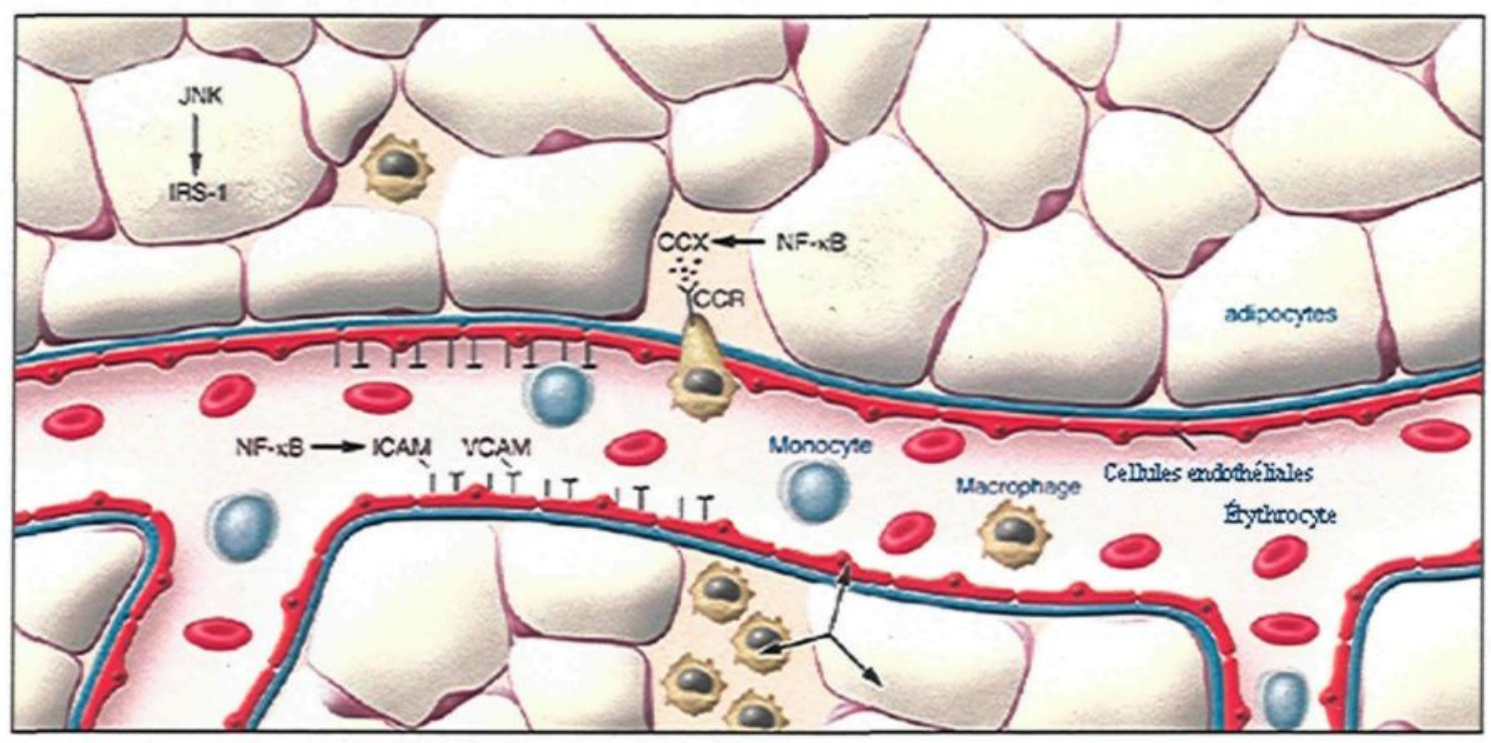

Figure 2 : Inflammation dans le tissu adipeux.

Modifié de Shoelson et al., $2006^{105}$.

Un stress cellulaire causé par une accumulation de lipides dans les adipocytes provoquerait l'activation de c-Jun NH2-terminal kinase (JNK) et du Nuclear factor-kappa binding (NF$\mathrm{kB})$. Ces voies de signalisation inflammatoires régulent la phosphorylation et la transcription cellulaire des protéines, ce qui conduit à la production accrue par les adipocytes de cytokines pro-inflammatoires, incluant le TNF- $\alpha$, l'IL- 6 , la leptine et la résistine, ainsi que des chimiokines comme MCP-1. Les molécules d'adhésion endothéliales 
(ICAM-1 et VCAM-1) et les molécules chimiotactiques (CCX) se lient aux intégrines et aux récepteurs de chimiokines (CCR), respectivement, à la surface des monocytes afin de recruter ceux-ci dans le tissu adipeux. Les monocytes se différencient en macrophages qui produisent plusieurs des cytokines et des chimiokines inflammatoires énumérées ci-dessus, ainsi que d'autres, ce qui accentue davantage l'inflammation locale et permet la propagation de la diathèse inflammatoire systémique ${ }^{105}$.

\subsubsection{LES CYTOKINES PRO-INFLAMMATOIRES ET LES CHIMIOKINES SÉCRÉTÉES DANS LE TISSU ADIPEUX}

L'obésité est caractérisée par un état d'inflammation chronique, avec une augmentation des taux circulants de plusieurs biomarqueurs de l'inflammation. Ces biomarqueurs comprennent la Protéine $C$-réactive ( $C$ reactive protein : $\mathrm{CRP}$ ), l'interleukine (IL)-6, l'haptoglobine, le sérum amyloïde $\mathrm{A}$, le TNF- $\alpha$, la monocyte chemoattractant protein (MCP)-1 et le migration inhibitory factor (MIF) ${ }^{75,76}$. L'état inflammatoire dans le tissu adipeux jouerait un rôle important dans l'apparition et le développement des maladies liées à l'obésité, en particulier le diabète de type 2 et les maladies cardiovasculaires ${ }^{72.76}$.

Il y a trois grands groupes d'adipokines liées à l'inflammation : les cytokines, les chimiokines et les protéines de phase aiguë ${ }^{70}$. Les principales protéines de phase aiguë produites par les adipocytes sont l'haptoglobine, le plasminogen activator inhibitor (PAI)-1 (qui est impliqué dans l'hémostase) et le sérum amyloïde A. Une gamme étendue de cytokines et de chimiokines qui sont synthétisées et sécrétées par les adipocytes ont maintenant été identifiées et ils comprennent entre autres le TNF- $\alpha$, l'IL-1 $\beta$, l'IL-6, l'IL-8, l'IL-10, la MCP-1, le MIF, le tumor growth factor beta (TGF $\beta$ ), l'ostéopontine (OPN) et la chemerine ${ }^{70-74,106,107 .}$ 
Le TNF- $\alpha$ et l'IL-6 sont des cytokines citées à maintes reprises dans la littérature puisqu'elles font l'objet d'un effort de recherche important dans le domaine de l'obésité ${ }^{108}$. La MCP-1 est une chimiokine impliquée dans le recrutement des monocytes dans le tissu adipeux, qui est considéré comme un processus important dans l'inflammation observé dans cette pathologie ${ }^{89}$. Ces molécules seront traitées sous l'aspect de leur implication dans le processus inflammatoire observé dans le tissu adipeux obèse.

\subsubsection{Tumor necrosis factor alpha (TNF)- $\alpha$}

Les concentrations de TNF- $\alpha$ circulant sont élevées chez les sujets obèses et chutent après la perte de poids ${ }^{109}$. Le TNF- $\alpha$ est plus exprimé dans le tissu adipeux de personnes obèses ${ }^{110}$. Le TNF- $\alpha$ est également plus exprimé dans les dépôts de graisses viscérales que sous-cutanées, et plus abondamment produit par les cellules de la fraction stroma-vasculaire (principalement les macrophages) que par les adipocytes ${ }^{110,111}$. La plupart des effets du TNF- $\alpha$ sur le tissu adipeux sont médiés par le TNF- $\alpha$ receptor 1 (TNFR1) et l'activation subséquente des différentes voies de signalisation ${ }^{112}$. Deux voies de signalisation par des facteurs de transcription ont été liées à des effets pro-inflammatoires reliés à l'obésité et à l'insulinorésistance : la voie du Nuclear factor-kappa binding (NF-kB) et la voie du c-Jun NH2-terminal kinase (JNK). Ces voies sont activées en majeure partie par les mêmes stimuli pro-inflammatoires, notamment des cytokines telles que le TNF- $\alpha$, qui en plus d'être des activateurs de NF-kB sont également des produits régulés par NF-kB ${ }^{113}$. Les JNK sont connues pour être activées en réponse à de nombreux stress cellulaires et en réponse aux cytokines inflammatoires, y compris le TNF- $\alpha$. Les études génétiques ont démontrées que JNK1 est un facteur important qui contribue à l'évolution de phénotypes liés à l'obésité tel que l'insulinorésistance. Une déficience en JNK1 améliore également la résistance à l'insuline chez des modèles de rongeurs obèses ${ }^{114}$. Le traitement systémique de souris 
obèses et résistantes à l'insuline avec un peptide qui inhibe l'activité kinase des JNK, réduit également la résistance à l'insuline dans des modèles murins d'obésité ${ }^{115}$.

Le génome du rat Zucker fa/fa est caractérisé par une mutation dans le gène du récepteur de la leptine, ce qui rend le modèle animal obèse et insulinorésistant. En 1993, Hotamisligil et al. ${ }^{67}$ n'ont pas seulement montré que le TNF- $\alpha$ était élevé dans le plasma du tissu adipeux des rongeurs obèses, mais ils ont aussi découvert que la neutralisation du TNF- $\alpha$ chez des rats Zucker $f a / f a$ obèses entraîne une augmentation significative de la captation périphérique du glucose en réponse à l'insuline. Ces données indiquent clairement un rôle pour le TNF- $\alpha$ dans la résistance à l'insuline et le diabète de type 2 qui accompagnent souvent l'obésité ${ }^{67}$.

Outre son effet sur la régulation à la hausse des adipokines pro-inflammatoires ${ }^{110}$ 116, 117, le TNF- $\alpha$ régule à la baisse les adipokines anti-inflammatoires, telles que l'adiponectine (ADIPOQ) ${ }^{118,119}$. La culture des adipocytes omentaux humains dans des milieux préalablement conditionnés par les cellules de la fraction stroma-vasculaire du tissu adipeux, qui est une des principales sources de TNF- $\alpha$, a provoqué une surproduction d'adipokines pro-inflammatoires. Cela a été abrogée par immunoneutralisation du TNF- $\alpha$ dans ces milieux, indiquant ainsi que, parmi les nombreux facteurs sécrétés par les cellules de la fraction stroma-vasculaire, le TNF- $\alpha$ est un contributeur essentiel au dérèglement de la production et sécrétion des adipokines par les adipocytes ${ }^{110}$.

\subsubsection{Interleukine (IL)-6}

L'IL-6 est une cytokine produite par plusieurs cellules (fibroblastes, cellules endothéliales, monocytes, adipocytes) ${ }^{120}$. La libération in vivo de l'IL-6 par l'ensemble du tissu adipeux corporel pourrait contribuer à une proportion de 15 à $35 \%$ de l'IL-6 systémique chez l'homme ${ }^{121}$. Les concentrations d'IL-6 circulantes et sa production sont 
augmentées dans l'obésité et sont principalement associées à la résistance à l'insuline ${ }^{120}$. Les fragments de tissu adipeux viscéral humain libèrent de deux à trois fois plus d'TL-6 in vitro que ceux du tissu adipeux sous-cutané, et les cellules de la fraction stroma-vasculaire contribuent essentiellement à la libération totale observée ${ }^{122}$. Tout comme le TNF- $\alpha$, l'IL-6 régule à la baisse 1'ADIPOQ ${ }^{118}$. L'IL-6 pourrait jouer un rôle central dans le lien entre l'obésité, l'inflammation et les maladies coronariennes ${ }^{123}$.

La concentration plasmatique moyenne de l'IL-6, mais pas celle du TNF- $\alpha$, ni celles de la leptine ou de la Monocyte chemoattractant protein (MCP)-1, a été retrouvé à 50\% plus élevée dans la veine porte que dans l'artère radiale de sujets obèses, et cette concentration d'IL-6 dans la veine porte était directement corrélée avec la concentration systémique de CRP ${ }^{124}$. Cela démontre que l'IL-6 serait un lien biologique important entre l'obésité, l'inflammation et les maladies coronariennes, car la CRP est un marqueur de l'inflammation et également une cause directe de maladies cardiovasculaires ${ }^{125}$. L'administration d'IL-6 recombinante chez les modèles de rongeurs et chez l'homme a résulté en une hyperglycémie et une hyperinsulinémie compensatoire ${ }^{126}$. Ainsi, l'IL-6 issue de dépôts de graisse omentaux passe directement dans le foie et, par conséquent, stimule la synthèse et la sécrétion des triglycérides hépatiques ${ }^{127}$. Par ailleurs, plusieurs études réalisées chez des modèles animaux et chez l'homme ont montré que l'IL-6 augmente la sensibilité des muscles squelettiques à l'insuline ${ }^{128}$, ce qui souligne l'importance de poursuivre les recherches fonctionnelles sur les effets de l'IL-6 afin de clarifier son rôle métabolique dans différents tissus.

\subsubsection{Monocyte chemoattractant protein (MCP)-1}

L'infiltration du tissu adipeux par les macrophages est un événement important dans le processus d'augmentation de l'inflammation observée dans l'obésité. La MCP-1, aussi connue comme la Chemokine (CC motif) Ligand 2 (CCL2), est un puissant facteur 
chimiotactique jouant un rôle dans le recrutement des monocytes dans le tissu adipeux. Les concentrations de MCP-1 circulants sont élevées dans l'obésité ${ }^{129}$. Bien que la MCP-1 est produite par les deux types de tissu adipeux, elle est davantage exprimée dans les cellules de la fraction stroma-vasculaire que dans les adipocytes, et dans le tissu adipeux viscéral que dans le tissu adipeux sous-cutané, tel que démontré précédemment pour le TNF- $\alpha$ et l'IL-6 ${ }^{129}$.

La chimiokine MCP-1 et son récepteur (CCR2) sont requis pour l'infiltration des macrophages dans le tissu adipeux. Les souris déficientes (knock-out : KO) en MCP-1 ou CCR2 nourries avec un régime alimentaire riche en gras présentaient moins de macrophages et un profil génique moins inflammatoire dans le tissu adipeux avec une réduction de l'insulinorésistance et de stéatose hépatique ${ }^{130,131}$. Inversement, des souris conçues pour exprimer un transgène de MCP-1 dans le tissu adipeux présentaient un phénotype opposé ${ }^{130}$. Le traitement des adipocytes 3T3-L1 différenciées avec MCP-1 a diminué l'absorption du glucose stimulée par l'insuline et l'expression de plusieurs gènes adipogéniques ${ }^{132}$. Finalement, dans une large cohorte de caucasiens, un polymorphisme dans le gène $M C P-1$, qui pourrait nuire à l'expression de MCP-1 lors de la transcription, a été corrélé négativement avec la concentration plasmatique de MCP-1 et la prévalence de la résistance à l'insuline et du diabète de type $2^{133}$.

La chimiokine MCP-1 est également impliquée dans le recrutement des monocytes dans la paroi vasculaire artérielle, un événement majeur conduisant à des lésions athérosclérotiques. Les concentrations de MCP-1 circulants sont élevés chez les patients souffrant de maladie coronarienne ${ }^{134}$. Des souris susceptibles de développer l'athérosclérose et croisées avec des souris déficientes en MCP-1 ont démontré une réduction de lésions athérosclérotiques ${ }^{135}$. 
Tableau 1 : Adipokines et chimiokines produites dans le tissu adipeux et impliquées dans le métabolisme, l'homéostasie énergétique et les réactions inflammatoires

\begin{tabular}{|c|c|c|}
\hline Adipokine & Source ${ }^{I}$ & $\mathbf{Q}$ \\
\hline $\begin{array}{l}\text { Adiponectine } \\
\text { (ADIPOQ) }\end{array}$ & Adipocytes & $\begin{array}{l}\text { Augmente l'oxydation des acides gras avec } \\
\text { une réduction du taux d'acides gras, des } \\
\text { triglycérides et de la glycémie }\end{array}$ \\
\hline $\begin{array}{l}\text { Tumor necrosis } \\
\text { factor (TNF)- } \alpha\end{array}$ & $\begin{array}{l}\text { Adipocytes/ } \\
\text { macrophages }\end{array}$ & $\begin{array}{l}\text { Stimule la lipolyse }{ }^{137} \text { et l'inhibition de la } \\
\text { différenciation des adipocytes }{ }^{138} \text {, module la } \\
\text { synthèse de plusieurs adipokines }\end{array}$ \\
\hline $\begin{array}{l}\text { Interleukine-6 } \\
\quad \text { (IL-6) }\end{array}$ & $\begin{array}{l}\text { Adipocytes/ } \\
\text { macrophages }\end{array}$ & $\begin{array}{c}\text { Associée à l'hypertriglycéridémie }{ }^{127} \text { et à } \\
\text { l'insulinorésistance }\end{array}$ \\
\hline $\begin{array}{l}\text { Monocyte } \\
\text { chemoattractant } \\
\text { protein }(\mathrm{MCP})-1\end{array}$ & $\begin{array}{l}\text { Préadipocytes/ } \\
\text { adipocytes/ } \\
\text { macrophages }\end{array}$ & $\begin{array}{l}\text { Recrutement des monocytes dans le tissu } \\
\text { adipeux et insulinorésistance }{ }^{132} \text {, régule à la } \\
\text { baisse l'adiponectine }\end{array}$ \\
\hline $\begin{array}{l}\text { Interleukine-1 } \\
\text { (IL-1) }\end{array}$ & Macrophages & $\begin{array}{l}\text { Impliquée dans la régulation du métabolisme } \\
\text { lipidique }\end{array}$ \\
\hline $\begin{array}{l}\text { Interleukine-10 } \\
\text { (IL-10) }\end{array}$ & $\begin{array}{l}\text { Adipocytes/ } \\
\text { macrophages }\end{array}$ & $\begin{array}{l}\text { Inhibe la production de } \\
\text { plusieurs cytokines et chimiokines } \\
\text { inflammatoires, stimule le relargage de } \\
\text { cytokines anti-inflammatoires }\end{array}$ \\
\hline
\end{tabular}

Sources les plus importantes dans le tissu adipeux

${ }^{2}$ Principales fonctions documentées dans le contexte d'obésité 


\section{CHAPITRE 4}

\section{LE RÉCEPTEUR (CX3CR1) ET SES LIGANDS}

\subsection{LES CHIMIOKINES}

Les chimiokines, une des grandes familles de cytokines, sont des protéines solubles sécrétées par plusieurs types cellulaires qui exercent un contrôle sur la migration de cellules impliquées dans la réaction immunitaire en activant les récepteurs à 7 domaines transmembranaires couplés aux protéines G. Ce sont des cytokines dites chimioattractantes, c'est-à-dire qu'elles peuvent attirer des cellules cibles sur les sites d'inflammation. Les chimiokines sont divisées en quatre sous-familles: cystéine (C), cystéine-cystéine (CC), cystéine-acide aminé X-cystéine (CXC), cystéine-3 acides aminés X-cystéine (CX3C), regroupées selon l'espacement des deux cystéines près de la portion $\mathrm{N}$-terminale de la protéine, qui participent à une paire de liaisons disulfure ${ }^{142}$. Ces protéines de signalisation dirigent le trafic des leucocytes dans le processus inflammatoire normal, mais elles sont aussi impliquées dans de nombreuses maladies, y compris le sida/HIV-1, l'arthrite, l'asthme

et la maladie inflammatoire de l'intestin ou la maladie de Crohn ${ }^{143}$. Ainsi la signalisation des chimiokines est largement étudiée pour l'élaboration de traitements pharmaceutiques.

\subsection{LA FRACTALKINE (CX3CL1)}

La fractalkine (FKN), également connue sous le nom de CX3C ligand 1 (CX3CL1), est la seule représentante de la famille CX3C. C'est une protéine à 4 domaines exprimée sur la surface des cellules ou sécrétée sous forme soluble. La fractalkine associée à la 
membrane (m-FKN) intervient principalement dans l'adhérence cellulaire ${ }^{144}$. La fractalkine soluble (s-FKN) agit dans la chimioattraction ${ }^{145}$. La FKN membranaire se compose d'un domaine extracellulaire de 76 acides aminés relié à une tige prolongée, suivie par des domaines transmembranaires et intracellulaires de 34 acides aminés ${ }^{146,} 147$.

\subsection{L'ÉOTAXINE-3 (CCL26)}

Un autre ligand de CX3CR1 a été identifié. Il s'agit de l'éotaxine-3 (Chemokine CC motif ligand 26 (CCL26)) ${ }^{148}$ qui influence le recrutement et la survie des lymphocytes dans l'asthme ${ }^{149}$. L'éotaxine-3 est une cytokine appartenant à la famille des chimiokines CC. L'éotaxine-3 est exprimée entre autres par les cellules bronchiales épithéliales ${ }^{150}$ et les cellules endothéliales ${ }^{151}$. L'éotaxine-3 est chimiotactique pour les éosinophiles, les basophiles et les cellules Th2 ${ }^{151}$ en se liant au récepteur CCR3 ${ }^{152}$. L'éotaxine-3 est une protéine de 94 acides aminés ${ }^{152}$ dont le gène est situé sur le chromosome $7^{153}$.

\subsection{LE RÉCEPTEUR DE LA FRACTALKINE (CX3CR1)}

Le récepteur de fractalkine, $\mathrm{CX} 3 \mathrm{CR} 1$, a été identifié chez le rat comme un récepteur de chimiokine nommé RBS11 ${ }^{154}$. Son homologue humain est codé sur la région chromosomique $3 \mathrm{p} 21.3^{155}$. Le récepteur de la fractalkine (CX3CR1) est un récepteur à 7 domaines transmembranaires, couplé aux protéines $\mathrm{G}$ et est constitué de 355 acides aminés. Les études d'interaction de CX3CR1 avec son ligand démontrent que CX3CL1 se lie de façon spécifique avec une forte affinite ${ }^{147}$. Son domaine $\mathrm{N}$-terminal contient plusieurs sites de sulfatation qui augmentent les capacités de capture et d'adhésion de CX3CR1 ${ }^{156}$.

Le récepteur de la fractalkine, CX3CR1, est exprimé sur les monocytes ${ }^{157}$ les lymphocytes $\mathrm{T}$ (particulièrement de type $\mathrm{Th} 1)^{147}$, les mastocytes ${ }^{158}$, les Natural killer 
(NK) cells ${ }^{159}$, les cellules dendritiques ${ }^{160}$, les plaquettes ${ }^{161}$, les neurones, les astrocytes et les cellules microgliales ${ }^{162}$ et joue un rôle dans les fonctions d'adhérence et de chimiotactisme de la fractalkine reliées aux processus de réponse inflammatoire ${ }^{163,164}$.

Deux polymorphismes connus et documentés du gène $C X 3 C R 1$, qui se trouvent dans les sixième et septième domaines transmembranaires du récepteur de la fractalkine, CX3CR1, soit V249I (rs3732379) et T280M (rs3732378), ont été associés à des maladies inflammatoires telles que l'athérosclérose ${ }^{165}$ et l'asthme ${ }^{166}$.

Cependant, des résultats contradictoires concernant les conséquences fonctionnelles des polymorphismes V249I et T280M de CX3CR1 ont été rapportés. Les allèles I249 et M280 ont été associés à un effet protecteur sur les artères coronaires étant donné le nombre plus faible de sites de liaison à la surface de la cellule ayant pour conséquence une affinité réduite pour le ligand CX3CL1 ${ }^{167-169}$. Cela a été remis en cause, car une étude a montré que les monocytes portant l'haplotype CX3CR1-IM adhèrent plus fortement que les ceux portant l'haplotype CX3CRI-VT ${ }^{170}$ et que le chimiotactisme des monocytes portant l'haplotype $C X 3 C R I$-IM est altéré en présence de CX3CL1 lié à la membrane ${ }^{171}$. Les allèles I249 et M280 n'ont pas généré un effet protecteur contre les accidents vasculaires cérébraux ischémiques ${ }^{172,173}$, ni contre la maladie artérielle périphérique ${ }^{174}$. De plus, chez les mêmes patients, les allèles I249 et M280 ont été associées à la fois à un risque accru d'infarctus du cerveau et une fréquence réduite de maladies coronariennes ${ }^{173}$. Étrangement, la présence de l'allèle M280 est associée à une diminution de l'épaisseur de l'intima-média dans l'artère carotide, alors que la présence de l'allèle 1249 ne joue pas un rôle majeur sur la progression de l'athérosclérose dans l'artère carotide ${ }^{175}$. À l'inverse, une étude épidémiologique menée chez des patients subissant une pose de stent (tuteur endovasculaire) dans l'artère coronaire a révélé un lien entre les polymorphismes communs de CX3CR1 et un risque élevé de resténose ${ }^{176}$. 
De plus, les associations rapportées par Tremblay et al. ${ }^{166}$ entre l'asthme et des polymorphismes de CX3CR1 dont V249I et T280M dans une population Canadienne française n'a été répliquée que partiellement dans une étude Allemande avec des sujets asthmatiques ${ }^{177}$, c'est-à-dire que l'association a été observée avec l'atopie mais pas avec l'asthme. Une autre étude menée en Tunisie sur des sujets asthmatiques n'a démontré aucune association entre l'asthme et les polymorphismes communs de $C X 3 C R I^{178}$.

\subsection{LE COMPLEXE CX3CL1/CX3CR1}

Le rôle de CX3CL1 a été investigué dans deux modèles murins d'athérosclérose. Une diminution de la formation de lésions athérosclérotiques dans l'artère brachiocéphalique et l'aorte a été observée ${ }^{179}$. La fractalkine (CX3CL1) peut agir par l'intermédiaire de CX3CR1 sur les cellules endothéliales pour promouvoir l'expression de la molécule d'adhésion intercellulaire ICAM-1 et l'adhérence des neutrophiles en activant la voie des Janus kinase/signal transducers and activators of transcription (Jak-Stat) $5^{180}$. De plus, CX3CL1 contribue au dysfonctionnement vasculaire en stimulant la libération de reactive oxygen species (ROS) vasculaires et par la réduction de la biodisponibilité de l'oxyde nitrique (Nitric Oxyde NO) dans des aortes isolées chez des rats ${ }^{181}$.

Deux études indépendantes sur la fonction du récepteur CX3CR1 ont démontré une réduction significative dans le recrutement des macrophages sur la paroi des vaisseaux et une diminution de la formation des lésions athérosclérotiques ${ }^{165,182}$. Récemment, les souris triple knock-out ont montré que la suppression génétique combinée de CCR2 et CX3CL1 conduit à une réduction spectaculaire des lésions d'athérosclérose chez les souris CX3CL1/-CCR2-/-ApoE-/- fournissant les preuves in vivo des rôles indépendants pour CX3CL1 et CCR2 dans le recrutement des monocytes vers les lésions athérosclérotiques ${ }^{183}$. De plus, l'inhibition de MCP-1 (CCL2), CX3CR1 et CCR5 chez des souris ApoE-/- est associée à 
une réduction de 90\% de l'athérosclérose, suggérant ainsi que CX3CR1, MCP-1 et CCR5 jouent un rôle indépendant et additif dans l'athérogenèse ${ }^{184}$. 


\section{CHAPITRE 5}

\section{ASSOCIATION ENTRE L'OBÉSITÉ ET DES POLYMORPHISMES COMMUNS}

DANS LE RÉCEPTEUR DE LA FRACTALKINNE (CX3CRI) 


\section{$2.1 \quad$ AVANT-PROPOS}

Le Dre Catherine Laprise, professeure-chercheure de l'Université du Québec à Chicoutimi, qui est ma directrice de recherche, a fait le profil méthodologique de l'étude, et a supervisé le travail de laboratoire ainsi que toutes les étapes menant à la publication du manuscrit.

Le Dr Daniel Gaudet, directeur du Centre de médecine génique communautaire (CMGC) de l'Université de Montréal, a conçu l'échantillon cas-témoins d'obésité, ce qui inclut le recrutement, l'évaluation clinique, l'extraction d'ADN des lymphocytes, la gestion de ceux-ci ainsi que la table phénotypique permettant de relier les ADNs codifiés aux phénotypes d'obésité. Le Dr Gaudet a également révisé le manuscrit.

Le Dre Diane Brisson, professionnelle de recherche au CMGC, a collaboré aux analyses statistiques ainsi qu'à la rédaction de l'article.

Stéphanie Perron a participé à la mise au point de la technique de génotypage.

Annie Chamberland a collaboré à la rédaction de l'article.

J'ai pour ma part contribué à cette étude en effectuant les manipulations dans le laboratoire, ce qui inclut la mise au point d'une nouvelle technique de génotypage, ainsi qu'en procédant aux analyses statistiques des données. J'ai rédigé l'article scientifique.

Cet article a été accepté pour fin de publication à la revue Obesity le 3 mai 2010. 
Association of common polymorphisms in the fractalkine receptor $(C X 3 C R I)$ with obesity

Authors: Dave Sirois-Gagnon ${ }^{1}$, Annie Chamberland ${ }^{1}$, Stéphanie Perron ${ }^{1}$, Diane Brisson ${ }^{2}$, Daniel Gaudet ${ }^{2}$, Catherine Laprise ${ }^{1,2}$

${ }^{1}$ Département des sciences fondamentales, Université du Québec à Chicoutimi, Saguenay, QC, G7H 2B1, Canada

2 Department of Medicine, Université de Montréal, ECOGENE-21 and Lipid Clinic, Chicoutimi Hospital, Saguenay, QC, Canada

Corresponding Author:

Catherine Laprise, Ph.D.

Université du Québec à Chicoutimi

555, boulevard de l'Université, Saguenay, QC, G7H 2B1, Canada

Telephone: (418) 545-5011, 5659

Fax: (418) 615-1203

Email: catherine_laprise@uqac.ca 


\section{Abstract}

The inflammatory component in obesity is now well established. The $C X 3 C R I$ gene encodes the fractalkine (CX3CL1) receptor and has two coding single nucleotide polymorphisms (SNPs), V249I and T280M, linked to a lower risk of other inflammatory diseases such as coronary artery disease and asthma. To determine whether $C X 3 C R I$ is associated with obesity, we genotyped the V249I and T280M polymorphisms of the $C X 3 C R I$ gene in subjects with a body mass index $(B M I) \geq 30 \mathrm{~kg} / \mathrm{m}^{2}$ and non obese controls with a BMI $<30 \mathrm{~kg} / \mathrm{m}^{2}$. Binary logistic regression analyses revealed that the $280 \mathrm{MM}$ genotype was associated with obesity $(P=0.022)$. A gender-specific one-way analysis of variance was also conducted to investigate mean BMI and waist circumference differences between genotypes of each polymorphism. For both polymorphisms independently, women carrying two copies of the minor allele had significant higher mean waist circumference than those carrying only one copy of the minor allele $(\mathrm{MM}>\mathrm{TM}, P=0.031$; II $>\mathrm{VI}, P=$ $0.013)$ or those who were homozygous for the major allele $(\mathrm{MM}>\mathrm{TT}, P=0.005 ; \mathrm{II}>\mathrm{VV}$, $P=0.006)$. We also observed significant higher mean waist circumference in men carrying one copy of the minor allele when compared to those who were homozygous for the major allele for the T280M polymorphism (TM $>\mathrm{TT}, P=0.029)$. This study suggests that $C X 3 C R 1$, a biomarker of obesity in this sample, constitutes a potential target for further investigation of the role of inflammation in the expression of obesity related phenotypes.

Key words: obesity, inflammation, body mass index, waist circumference, CX3CR1 


\section{Introduction}

According to data from the World Health Organization (WHO), obesity has reached epidemic proportions worldwide, with more than 1 billion adults overweight worldwide (body mass index $(\mathrm{BMI})>25 \mathrm{~kg} / \mathrm{m}^{2}$ ), and at least 300 million being clinically obese (BMI $>30 \mathrm{~kg} / \mathrm{m}^{2}$ ). Obesity is a complex trait not following classical Mendelian transmission pattern, implying that it is influenced by interplay between genes, environment and lifestyle. Recent studies using different approaches showed several susceptibility genes with low or moderate effects (1). Obesity is a chronic inflammatory disease which confers important cardiometabolic and cardiorespiratory risks. Obesity is also recognized to be associated with inflammatory components characterized by abnormal cytokine production and activation of inflammatory signaling pathways in adipose tissue (2). The $C X 3 C R I$ gene, coding for the seven-transmembrane domain $G$ protein-coupled receptor of the chemokine fractalkine (CX3CL1), plays a role in leukocyte signaling and their migration to inflammatory sites and modulates the actions of immunocompetent cells in inflammatory diseases $(3,4)$. The chemokine receptor CX3CR1 and its ligand CX3CL1 have been implicated in many inflammatory diseases, including coronary artery disease (CAD) (5), hypertension (6), rheumatoid arthritis (7), liver disease (8) and acquired immune deficiency syndrome (AIDS) (9). V249I and T280M, two common single nucleotide polymorphisms (SNPs) of the CX3CRI gene, have been described (10) and associated with protection against CAD (11-13) and asthma (14).

It is well recognized that there are marked differences in the amount and distribution of body fat and in whole-body lipid metabolism between men and women (15). Many gender- 
specific associations between polymorphisms and overweight have also been found (1621).

Based on these observations and since obesity is characterized as an inflammatory condition, we hypothesized that the CX3CL1/CX3CR1 pathway might also be implicated in obesity expression. We performed a case-control association study using obese patients with a body mass index $(\mathrm{BMI}) \geq 30 \mathrm{~kg} / \mathrm{m}^{2}$ and non-obese controls with a $\mathrm{BMI}<30 \mathrm{~kg} / \mathrm{m}^{2}$ and conducted a gender-specific one-way analysis of variance to test mean BMI and waist circumference differences between genotypes of each polymorphism. We found that V249I and T280M polymorphisms of the $C X 3 C R 1$ gene were associated with obesity.

\section{Material and methods}

\section{Subjects and clinical data}

This study comprised a sample of 900 French Canadians (633 with BMI < 30 and 267 with BMI $\geq 30$ ). All subjects were clinically evaluated at the Chicoutimi Hospital Lipid Clinic. Clinical phenotypes frequently associated with obesity were evaluated in all participants. Type 2 diabetes was diagnosed in the presence of 2 values of fasting glucose concentrations $\geq 7.0 \mathrm{mmol} / \mathrm{L}$ or $2-\mathrm{h}$ glucose concentration $>11.1 \mathrm{mmol} / \mathrm{L}$ following a standard $2 \mathrm{~h}$ oral glucose tolerance test (OGTT) after ingestion of $75 \mathrm{~g}$ of glucose. BMI was calculated as weight in kilograms divided by squared height in meters $\left(\mathrm{kg} / \mathrm{m}^{2}\right)$. Waist circumference, body weight and height were measured according to the procedures recommended at the Airlie Conference (22). The presence of CAD was determined using the AHA criteria and based on clinical history and clinically documented myocardial infarction or angiographic 
evidence of coronary lesions, as previously described $(23,24)$. Blood samples were obtained after a 12-hour overnight fast. Plasma total cholesterol, triglyceride and highdensity lipoprotein (HDL)-cholesterol levels were measured with enzymatic essays (25). Total cholesterol was determined in plasma and HDL-cholesterol was measured in the supernatant after precipitation of very low-density lipoprotein (VLDL) and low-density lipoprotein (LDL) with dextran sulfate in magnesium chloride (26). Plasma LDLcholesterol levels were estimated using the Friedewald formula (27). Subjects gave informed consent to participate in this study and were assigned a code that systematically denominalizes all clinical data (28). This project has received the approval from the Chicoutimi Hospital Ethics Committee.

\section{PCR-High Resolution Melt conditions}

Genomic DNA was extracted from whole blood leukocytes using Genomic -Tip 100/G kit (Qiagen, Inc., Valencia, CA). Genotyping of the V249I (rs3732379) and T280M (rs3732378) polymorphisms was performed using High Resolution Melt (HRM) technique. All information regarding the technique is available in Reed et al (29). Briefly, real-time PCR and melting curve analysis (MCA) are state-of-the-art techniques for quantifying nucleic acids, for mutation detection, and for genotyping analysis. We used SYTO 9 (Invitrogen, Carlsbad CA, USA), a DNA intercalating dye which binds to and saturates double-stranded DNA. SYTO 9 produces much higher fluorescence when bound to doublestranded DNA compared to the unbound state. Indication of specific amplification is subsequently obtained by analysis of the melting curve of the PCR amplicons. The amplicon DNA is heated at temperatures gradually increasing. When the melting 
temperature of the amplicon is reached, the sample of DNA denatures, passing from double-stranded to single-stranded DNA which result in fluorescence diminution. A Melting Curve is generated by plotting the level of fluorescence in function of the temperature. Single base change in the sample DNA sequence causes differences in the HRM curve and can be used to assign the genotypes. Protocols, primers, PCR and HRM conditions are available on demand.

\section{Statistical analysis}

The gene counting method estimated allele frequencies and the Pearson chi-square statistic were used to identify deviations from Hardy-Weinberg equilibrium (HWE). Student's unpaired two-tailed $t$-test was used to compare continuous variables whereas categorical variables were compared using the chi-square statistic. Triglyceride levels were $\log _{10}$ transformed because of their skewed distribution. Multivariate logistic regression models were built in order to calculate the relative odds of exhibiting obesity (as defined by a BMI $\geq 30$ ) associated with the presence of V249I and T280M polymorphisms. Odds ratio (OR) and $95 \%$ confidence interval (CI) were obtained taking into account the effect of BMI confounders, namely age, gender, type 2 diabetes, CAD and LDL-cholesterol. Effects of discrete variables were evaluated dichotomously, according to their absence or presence in subjects. One-way analyses of variance were used to test for mean BMI and waist circumference differences between genotypes for men and women separately, followed by the Bonferroni post hoc tests. Statistical analysis was performed using SPSS 11.5 (SPSS, Inc., Chicago, USA). 


\section{Results}

As shown in table 1 , female to male ratio was the same for controls and cases. Mean age was comparable in controls and cases. Mean values for BMI, waist circumference, triglycerides and glycemia were higher in cases than those observed in controls. As expected, plasma mean HDL-cholesterol concentrations in controls were slightly higher than those of cases. Plasma mean LDL-cholesterol concentrations in controls were also higher than those of cases. The proportion of patients with diabetes was significantly higher in cases $(36.0 \%)$ than in controls $(12.8 \%)(P<0.05)$. The proportion of patients with CAD was approximately the same in cases $(34.8 \%)$ than in controls $(30.0 \%)$.

The genotype frequencies were in accordance with the HWE for the V249I polymorphism (Sample, $P=0.466$; Controls, $P=0.083$; Cases, $P=0.471$ ). Departures from HWE were detected in the genotype frequencies of the T280M polymorphism (Sample, $P<0.001$; Controls, $P=0.003$; Cases, $P=0.004)$.

The ORs associated with an increased BMI for the different genotypes of V249I and T280M are shown in Table 2. Taking into account the effect of BMI confounders, namely age, gender, type 2 diabetes, CAD and LDL-cholesterol, the association between MM genotype and obesity was $2.497(95 \% \mathrm{CI}, 1.396-4.469 ; P=0.002)$. After correction for multiple testing, the MM genotype was still significantly associated with obesity ( $P$ corrected $=0.022$ ) 
Significant waist circumference differences were found. Women mean waist circumference values were $84.0,85.1$ and $91.3 \mathrm{~cm}$ in the TT, TM and MM genotypes, respectively (MM > TT, $P=0.005 ; \mathrm{MM}>\mathrm{TM}, P=0.031$ ) for the T280M polymorphism. Similar results were obtained for the V249I polymorphism as the mean waist circumference values for women were $84.0,84.4$ and $89.8 \mathrm{~cm}$ in the VV, VI and II genotypes, respectively (II $>\mathrm{VV}, P=$ 0.006; II > VI, $P=0.013$ ). Men mean waist circumference values were $93.2,96.7$ and 94.9 $\mathrm{cm}$ in the TT, TM and MM genotypes, respectively (TM $>\mathrm{TT}, P=0.029)$ for the T280M polymorphism (Table 3).

The association of $C X 3 C R 1$ polymorphisms with age, gender, type 2 diabetes, CAD, fasting glucose, HDL-cholesterol, LDL-cholesterol or triglycerides was not independent of the presence of obesity and did not show a significant association when the BMI or the waist circumference were included in the models (data not shown).

\section{Discussion}

One of the greatest economic health burdens in the world is the "metabolic syndrome" (MS). This cluster of obesity related risk factors (including abnormal glucose metabolism, dyslipidemia, pro-inflammatory profile) frequently found together, greatly increases an individual's chances of developing chronic diseases such as type 2 diabetes, CAD, cardiorespiratory or other health complications. Thus, documenting the contribution of proinflammatory genetic determinants to obesity may yield important health knowledge. 
Since last three years, the Genome Wide Association Studies allow the identification of novel genetic determinants (e.g. fat mass and obesity associated (FTO) (30), phosphotriesterase related (PTER) (31), catenin, beta-like 1 (CTNNBL1) (32)), as well as validation of the implication of genes in obesity (e.g. melanocortin 4 receptor $(M C 4 R)$ (33)). However, other methodological approaches, which use more modest cohort with better subject characterization and hypothesis driven design should, as the present study, also contribute to increase the knowledge on the genetics of the studied trait.

Fractalkine is a chemokine interacting with its receptor CX3CR1 implicated in many inflammatory diseases (5-8) and the gene coding for this receptor is a potential candidate for obesity and associated risks. Our data indicate that M280 allele frequency is significantly higher among the obese participants in this study. The results showed herein suggest that the $280 \mathrm{MM}$ genotype is associated with obesity and support the hypothesis that the CX3CL1/CX3CR1 system might play a role also in obesity and be part of the cluster of metabolic disturbances which characterize the MS.

In this study, women subjects carrying two copies of the M280 allele showed significant increase of mean waist circumference when compared to those carrying one copy of the M280 allele or those carrying only the T280 allele. Similar results were obtained for women subjects carrying two copies of the I249 allele. Men carrying one copy of the M280 allele showed a significant increase of mean waist circumference. These results indicate that the two common polymorphisms of CX3CR1 T280M and V249I both increase the mean waist circumference with some gender-specific effects. Other studies have found 
gender-specific associations between polymorphisms and obesity (16-21). This is consistent with the well documented gender differences observed in fat distribution and lipid metabolism (15). The importance of considering gender-specific differences in research has recently been reviewed by Kautzky-Willer and Handisurya (34). Differences in phenotype between men and women (body composition, regional fat distribution) affect substrate metabolism. There are also differences between the sexes in the lipid profile and metabolism. Lovejoy and Sainsbury recently reviewed these differences between men and women in the context of energy expenditure (35).

In conclusion, this study suggests that the T280M and V249I polymorphisms of the $C X 3 C R 1$ gene are associated with obesity. Further studies are required to establish the role of the $\mathrm{CX} 3 \mathrm{CR} 1$ in obesity and its clinical cardiometabolic consequences.

\section{Acknowledgments}

We thank all the study participants. Thanks to the CMGC medical staff and to Denise Morin and Nadia Mior for samples processing and DNA extraction. D. Gaudet is the chairholder of the Canada Research Chair in Preventative Genetics and Community Genomics. C. Laprise is the chairholder of the Canada Research Chair on Genetic Determinants of Asthma. This obesity case-control study was financially supported by the ECOGENE-21 project (CIHR TEAM grant \# CTP-82941). 


\section{References}

1 Walley AJ, Asher JE, Froguel P. The genetic contribution to non-syndromic human obesity. Nat Rev Genet 2009;10:431-42.

2 Hotamisligil GS. Inflammation and metabolic disorders. Nature 2006;444:860-7.

3 Imai T, Hieshima K, Haskell C, et al. Identification and molecular characterization of fractalkine receptor CX3CR1, which mediates both leukocyte migration and adhesion. Cell 1997;91:521-30.

4 Combadiere C, Salzwedel K, Smith ED, Tiffany HL, Berger EA, Murphy PM. Identification of CX3CR1. A chemotactic receptor for the human $\mathrm{CX} 3 \mathrm{C}$ chemokine fractalkine and a fusion coreceptor for HIV-1. The Journal of biological chemistry 1998;273:23799-804.

5 Wong BW, Wong D, McManus BM. Characterization of fractalkine (CX3CL1) and CX3CR1 in human coronary arteries with native atherosclerosis, diabetes mellitus, and transplant vascular disease. Cardiovasc Pathol 2002;11:332-8.

6 Timofeeva AV, Goryunova LE, Khaspekov GL, et al. Altered gene expression pattern in peripheral blood leukocytes from patients with arterial hypertension. Annals of the New York Academy of Sciences 2006;1091:319-35.

7 Volin MV, Woods JM, Amin MA, Connors MA, Harlow LA, Koch AE. Fractalkine: a novel angiogenic chemokine in rheumatoid arthritis. The American journal of pathology 2001;159:1521-30.

8 Efsen E, Grappone C, DeFranco RM, et al. Up-regulated expression of fractalkine and its receptor CX3CR1 during liver injury in humans. Journal of hepatology 2002;37:3947.

9 Foussat A, Bouchet-Delbos L, Berrebi D, et al. Deregulation of the expression of the fractalkine/fractalkine receptor complex in HIV-1-infected patients. Blood 2001;98:1678-86.

10 Faure S, Meyer L, Costagliola D, et al. Rapid progression to AIDS in HIV+ individuals with a structural variant of the chemokine receptor CX3CR1. Science (New York, N.Y 2000;287:2274-7.

11 McDermott DH, Halcox JP, Schenke WH, et al. Association between polymorphism in the chemokine receptor CX3CR1 and coronary vascular endothelial dysfunction and atherosclerosis. Circulation research 2001;89:401-7.

12 Moatti D, Faure S, Fumeron F, et al. Polymorphism in the fractalkine receptor CX3CR1 as a genetic risk factor for coronary artery disease. Blood 2001;97:1925-8.

13 McDermott DH, Fong AM, Yang Q, et al. Chemokine receptor mutant CX3CR1M280 has impaired adhesive function and correlates with protection from cardiovascular disease in humans. The Journal of clinical investigation 2003;111:1241-50.

14 Tremblay K, Lemire M, Provost V, et al. Association study between the CX3CR1 gene and asthma. Genes and immunity 2006;7:632-9.

15 Williams CM. Lipid metabolism in women. The Proceedings of the Nutrition Society 2004;63:153-60. 
16 Dallongeville J, Helbecque N, Cottel D, Amouyel P, Meirhaeghe A. The Gly16-$>$ Arg16 and Gln27-->Glu27 polymorphisms of beta2-adrenergic receptor are associated with metabolic syndrome in men. The Journal of clinical endocrinology and metabolism 2003;88:4862-6.

17 Fox CS, Yang Q, Cupples LA, et al. Sex-specific association between estrogen receptor-alpha gene variation and measures of adiposity: the Framingham Heart Study. The Journal of clinical endocrinology and metabolism 2005;90:6257-62.

18 Gonzalez Sanchez JL, Proenza AM, Martinez Larrad MT, et al. The glutamine 27 glutamic acid polymorphism of the beta2-adrenoceptor gene is associated with abdominal obesity and greater risk of impaired glucose tolerance in men but not in women: a population-based study in Spain. Clinical endocrinology 2003;59:476-81.

19 Hoffstedt J, Eriksson P, Hellstrom L, Rossner S, Ryden M, Arner P. Excessive fat accumulation is associated with the TNF alpha-308 G/A promoter polymorphism in women but not in men. Diabetologia 2000;43:117-20.

20 Meirhaeghe A, Helbecque N, Cottel D, Amouyel P. Impact of polymorphisms of the human beta2-adrenoceptor gene on obesity in a French population. Int J Obes Relat Metab Disord 2000;24:382-7.

21 Qi L, Shen H, Larson I, et al. Gender-specific association of a perilipin gene haplotype with obesity risk in a white population. Obesity research 2004;12:1758-65.

22 Lohman TG, Roche AF, Martorell R. Anthropometric standardization reference manual. 1988; Human Kinetics Books: Champaign, IL.

23 Gaudet D, Vohl MC, Perron P, et al. Relationships of abdominal obesity and hyperinsulinemia to angiographically assessed coronary artery disease in men with known mutations in the LDL receptor gene. Circulation 1998;97:871-7.

24 Gaudet D, Vohl MC, Julien P, et al. Relative contribution of low-density lipoprotein receptor and lipoprotein lipase gene mutations to angiographically assessed coronary artery disease among French Canadians. The American journal of cardiology 1998;82:299-305.

25 Burstein M, Samaille J. Sur un dosage rapide du cholestérol lié aux $\beta$-lipoprotéines du sérum. . Clin Chim Acta 1960;5:609.

26 Warnick G, Benderson J, Albers J. Dextran sulfate-Mg2+ precipitation procedures for quantitation of high-density lipoprotein cholesterol. Clin Chem 1982;28:1379-87.

27 Friedewald WT, Levy RI, Fredrickson DS. Estimation of the concentration of low density lipoprotein cholesterol in plasma, without use of the preparative ultracentrifuge. Clin Chem 1972;18:499-502.

28 Gaudet D, Arsenault S, Belanger C, et al. Procedure to protect confidentiality of familial data in community genetics and genomic research. Clinical genetics 1999;55:25964.

29 Reed GH, Kent JO, Wittwer CT. High-resolution DNA melting analysis for simple and efficient molecular diagnostics. Pharmacogenomics 2007;8:597-608.

30 Frayling TM, Timpson NJ, Weedon MN, et al. A common variant in the FTO gene is associated with body mass index and predisposes to childhood and adult obesity. Science (New York, N.Y 2007;316:889-94.

31 Meyre D, Delplanque J, Chevre JC, et al. Genome-wide association study for earlyonset and morbid adult obesity identifies three new risk loci in European populations. Nature genetics 2009;41:157-9. 
32 Liu YJ, Liu XG, Wang L, et al. Genome-wide association scans identified CTNNBL1 as a novel gene for obesity. Human molecular genetics 2008;17:1803-13.

33 Loos RJ, Lindgren CM, Li S, et al. Common variants near MC4R are associated with fat mass, weight and risk of obesity. Nature genetics 2008;40:768-75.

34 Kautzky-Willer A, Handisurya A. Metabolic diseases and associated complications: sex and gender matter! European journal of clinical investigation 2009;39:631-48.

35 Lovejoy JC, Sainsbury A. Sex differences in obesity and the regulation of energy homeostasis. Obes Rev 2009;10:154-67. 
Tableau 2 : TABLE 1- Clinical characteristics of the subjects studied

\begin{tabular}{|c|c|c|c|}
\hline Characteristics & $\begin{array}{c}\text { Subjects with BMI } \\
<30 \\
\mathrm{n}(633)\end{array}$ & $\begin{array}{c}\text { Subjects with BMI } \\
\geq 30 \\
\mathrm{n}(267)\end{array}$ & $P^{\mathrm{c}}$ \\
\hline $\operatorname{Sex}(f / m)$ & 1.04:1 & 1.02:1 & 0.933 \\
\hline Type 2 diabetes (\%) & 12.8 & 36.0 & $<0.001$ \\
\hline $\mathrm{CAD}(\%)$ & 30.0 & 34.8 & 0.155 \\
\hline Age (years) ${ }^{a}$ & $49.11 \pm 13.19$ & $50.48 \pm 11.75$ & 0.126 \\
\hline $\operatorname{BMI}\left(\mathrm{kg} / \mathrm{m}^{2}\right)^{\mathrm{a}}$ & $24.40 \pm 3.00$ & $32.65 \pm 2.00$ & $<0.001$ \\
\hline Waist circumference $(\mathrm{cm})^{\mathrm{a}}$ & $83.88 \pm 10.07$ & $103.71 \pm 9.71$ & $<0.001$ \\
\hline Glycemia $(\mathrm{mmol} / \mathrm{l})^{\mathrm{a}}$ & $5.28 \pm 1.32$ & $6.03 \pm 1.66$ & $<0.001$ \\
\hline HDL cholesterol $(\mathrm{mmol} / \mathrm{l})^{a}$ & $1.24 \pm 0.42$ & $1.10 \pm 0.40$ & $<0.001$ \\
\hline LDL cholesterol $(\mathrm{mmol} / \mathrm{l})^{a}$ & $4.21 \pm 1.88$ & $3.77 \pm 1.81$ & 0.002 \\
\hline Total cholesterol/HDL $(\mathrm{mmol} / \mathrm{l})^{a}$ & $5.92 \pm 2.96$ & $6.75 \pm 4.24$ & 0.009 \\
\hline Triglycerides $(\mathrm{mmol} / \mathrm{l})^{\mathbf{a}, \mathbf{b}}$ & $0.55 \pm 0.66$ & $0.90 \pm 0.81$ & $<0.001$ \\
\hline
\end{tabular}

\footnotetext{
${ }^{\mathrm{a}}$ Mean \pm SD

${ }^{\mathrm{b}}$ Geometric mean after $\log _{10}$-transformation were used for triglyceride levels

${ }^{\mathrm{c}} P$ value: $<0.05$

BMI: body mass index; CAD: coronary artery disease; HDL: high density lipoprotein; LDL: low density lipoprotein
} 
Tableau 3 : TABLE 2-Genotype odds ratios associated with obesity for the V249I and T280M variants of the CX3CR1 gene

\begin{tabular}{|c|c|c|c|c|c|c|c|}
\hline Polymorphisms & Genotypes & Controls & Cases & $\mathrm{OR}^{\mathrm{a}}$ & CI 95\% & $\overline{P^{\mathrm{C}}}$ & $\begin{array}{c}P^{\mathrm{d}} \\
\text { corrected }\end{array}$ \\
\hline \multirow{3}{*}{ V249I } & VV & 321 & 115 & & & & \\
\hline & VI & 251 & 118 & 1.270 & $\begin{array}{c}0.917- \\
1.758\end{array}$ & 0.150 & 1.000 \\
\hline & II & 61 & 34 & 1.523 & $\begin{array}{c}0.926- \\
2.504\end{array}$ & 0.097 & 1.000 \\
\hline \multirow{3}{*}{$\mathrm{T} 280 \mathrm{M}$} & TT & 446 & 158 & & & & \\
\hline & TM & 157 & 84 & 1.437 & $\begin{array}{c}1.017- \\
2.029\end{array}$ & 0.040 & 0.440 \\
\hline & MM & 30 & 25 & 2.497 & $\begin{array}{c}1.396- \\
4.469\end{array}$ & 0.002 & 0.022 \\
\hline
\end{tabular}

${ }^{\mathrm{a} O R}$ : Odds ratio adjusted for age, gender, type 2 diabetes, CAD and LDL-cholesterol

${ }^{\mathrm{b}} \mathrm{CI}$ : Confidence Interval

${ }^{\mathrm{c}} P$ value: $<0.05$

${ }^{\mathrm{d}}$ Using Bonferroni's correction 
Tableau 4 : TABLE 3-Gender-specific one-way analysis of variance of mean BMI and waist circumference differences between genotypes of the V249I and T280M polymorphisms of the $C X 3 C R 1$ gene

\begin{tabular}{|c|c|c|c|c|c|c|c|c|}
\hline \multicolumn{9}{|c|}{ BMI } \\
\hline \multirow{8}{*}{$\begin{array}{c}\text { Gender } \\
\text { Women }\end{array}$} & \multirow[t]{2}{*}{ (I) V249I } & \multirow[t]{2}{*}{ Mean } & \multirow[t]{2}{*}{$\begin{array}{c}(J) \\
\text { V249I }\end{array}$} & \multirow[t]{2}{*}{$\begin{array}{c}\text { Mean } \\
\text { Difference } \\
(\mathbf{I}-\mathbf{J}) \\
\end{array}$} & \multirow[t]{2}{*}{$\begin{array}{c}\text { Standard } \\
\text { Error }\end{array}$} & \multirow[t]{2}{*}{$P^{\mathbf{a}}$} & \multicolumn{2}{|c|}{ CI $95 \%^{b}$} \\
\hline & & & & & & & $\begin{array}{l}\text { Lower } \\
\text { Bound } \\
\end{array}$ & $\begin{array}{l}\text { Upper } \\
\text { Bound } \\
\end{array}$ \\
\hline & \multirow[t]{2}{*}{ VV (211) } & \multirow[t]{2}{*}{26.6} & VI & 0.1 & 0.4 & 1.000 & -1.0 & 1.1 \\
\hline & & & II & -1.6 & 0.7 & 0.079 & -3.3 & 0.1 \\
\hline & \multirow[t]{2}{*}{ VI (192) } & \multirow[t]{2}{*}{26.5} & VV & -0.1 & 0.4 & 1.000 & -1.1 & 1.0 \\
\hline & & & II & -1.6 & 0.7 & 0.064 & -3.4 & 0.1 \\
\hline & \multirow[t]{2}{*}{ II (47) } & \multirow[t]{2}{*}{28.1} & VV & 1.6 & 0.7 & 0.079 & -0.1 & 3.3 \\
\hline & & & VI & 1.6 & 0.7 & 0.064 & -0.1 & 3.4 \\
\hline \multirow[t]{6}{*}{ Men } & \multirow[t]{2}{*}{ VV (208) } & \multirow[t]{2}{*}{26.3} & VI & -1.0 & 0.5 & 0.090 & -2.1 & 0.1 \\
\hline & & & II & -0.1 & 0.7 & 1.000 & -1.8 & 1.6 \\
\hline & \multirow[t]{2}{*}{ VI (166) } & \multirow[t]{2}{*}{27.3} & VV & 1.0 & 0.5 & 0.090 & -0.1 & 2.1 \\
\hline & & & II & 0.9 & 0.7 & 0.670 & -0.9 & 2.6 \\
\hline & \multirow[t]{2}{*}{ II (45) } & \multirow[t]{2}{*}{26.4} & VV & 0.1 & 0.7 & 1.000 & -1.6 & 1.8 \\
\hline & & & VI & -0.9 & 0.7 & 0.670 & -2.6 & 0.9 \\
\hline \multirow[t]{2}{*}{ Gender } & \multirow[t]{2}{*}{$\begin{array}{c}\text { (I) } \\
\text { T280M }\end{array}$} & \multirow[t]{2}{*}{ Mean } & $\begin{array}{c}(\mathrm{J}) \\
\mathrm{T} 280 \mathrm{M}\end{array}$ & $\begin{array}{c}\text { Mean } \\
\text { Difference } \\
(\mathbf{I}-\mathbf{J}) \\
\end{array}$ & $\begin{array}{c}\text { Standard } \\
\text { Error }\end{array}$ & $P^{\mathrm{a}}$ & \multicolumn{2}{|c|}{ CI $95 \%{ }^{b}$} \\
\hline & & & & & & & $\begin{array}{l}\text { Lower } \\
\text { Bound }\end{array}$ & $\begin{array}{l}\text { Upper } \\
\text { Bound }\end{array}$ \\
\hline \multirow[t]{6}{*}{ Women } & \multirow[t]{2}{*}{ TT (291) } & \multirow[t]{2}{*}{26.6} & $\mathrm{TM}$ & -0.2 & 0.5 & 1.000 & -1.3 & 0.9 \\
\hline & & & $\mathrm{MM}$ & -2.0 & 0.8 & 0.053 & -4.0 & 0.0 \\
\hline & \multirow[t]{2}{*}{ TM (129) } & 26.8 & $\mathrm{TT}$ & 0.2 & 0.5 & 1.000 & -0.9 & 1.3 \\
\hline & & & $\mathrm{MM}$ & -1.8 & 0.9 & 0.138 & -3.9 & 0.4 \\
\hline & MM (30) & 28.6 & $\mathrm{TT}$ & 2.0 & 0.8 & 0.053 & 0.0 & 4.0 \\
\hline & & & TM & 1.8 & 0.9 & 0.138 & -0.4 & 3.9 \\
\hline Men & TT (296) & 26.3 & $\mathrm{TM}$ & -1.1 & 0.5 & 0.070 & -2.4 & 0.1 \\
\hline & & & $\mathrm{MM}$ & -1.3 & 0.9 & 0.443 & -3.5 & 0.9 \\
\hline & TM (98) & 27.4 & $\mathrm{TT}$ & 1.1 & 0.5 & 0.070 & -0.1 & 2.4 \\
\hline & & & $\mathrm{MM}$ & -0.2 & 1.0 & 1.000 & -2.5 & 2.2 \\
\hline & MM (25) & 27.6 & $\mathrm{TT}$ & 1.3 & 0.9 & 0.443 & -0.9 & 3.5 \\
\hline & & & $\mathrm{TM}$ & 0.2 & 1.0 & 1.000 & -2.2 & 2.5 \\
\hline
\end{tabular}




\begin{tabular}{|c|c|c|c|c|c|c|c|c|}
\hline \multicolumn{9}{|c|}{ Waist circumference } \\
\hline \multirow[t]{2}{*}{ Gender } & \multirow[t]{2}{*}{ (I) V249I } & \multirow[t]{2}{*}{ Mean } & \multirow[t]{2}{*}{$\begin{array}{c}(J) \\
\text { V249I }\end{array}$} & \multirow[t]{2}{*}{$\begin{array}{c}\text { Mean } \\
\text { Difference } \\
(\mathbf{I}-\mathbf{J}) \\
\end{array}$} & \multirow[t]{2}{*}{$\begin{array}{c}\text { Standard } \\
\text { Error }\end{array}$} & \multirow[t]{2}{*}{$P^{\mathrm{a}}$} & \multicolumn{2}{|c|}{ CI 95\% ${ }^{b}$} \\
\hline & & & & & & & $\begin{array}{l}\text { Lower } \\
\text { Bound }\end{array}$ & $\begin{array}{l}\text { Upper } \\
\text { Bound }\end{array}$ \\
\hline \multirow[t]{6}{*}{ Women } & VV (206) & 84.0 & VI & -0.4 & 1.1 & 1.000 & -3.1 & 2.4 \\
\hline & & & II & -5.8 & 1.9 & 0.006 & -10.2 & -1.3 \\
\hline & VI (186) & 84.4 & VV & 0.4 & 1.1 & 1.000 & -2.4 & 3.1 \\
\hline & & & II & -5.4 & 1.9 & 0.013 & -9.9 & -0.9 \\
\hline & II (45) & 89.8 & VV & 5.8 & 1.9 & 0.006 & 1.3 & 10.3 \\
\hline & & & VI & 5.4 & 1.9 & 0.013 & 0.9 & 9.9 \\
\hline \multirow[t]{6}{*}{ Men } & VV (205) & 93.4 & VI & -1.8 & 1.2 & 0.421 & -4.7 & 1.1 \\
\hline & & & II & 0.3 & 1.9 & 1.000 & -4.3 & 4.9 \\
\hline & VI (164) & 95.2 & VV & 1.8 & 1.2 & 0.421 & -1.1 & 4.7 \\
\hline & & & II & 2.1 & 1.9 & 0.836 & -2.6 & 6.8 \\
\hline & II (45) & 93.1 & VV & -0.3 & 1.9 & 1.000 & -4.9 & 4.3 \\
\hline & & & VI & -2.1 & 1.9 & 0.836 & -6.8 & 2.6 \\
\hline \multirow[t]{2}{*}{ Gender } & $\begin{array}{c}\text { (I) } \\
\text { T280M } \\
\end{array}$ & Mean & $\begin{array}{c}(\mathbf{J}) \\
\mathbf{T} 280 \mathrm{M} \\
\end{array}$ & $\begin{array}{c}\text { Mean } \\
\text { Difference } \\
(\mathbf{I}-\mathrm{J})\end{array}$ & $\begin{array}{c}\text { Standard } \\
\text { Error }\end{array}$ & $P^{\mathrm{a}}$ & \multicolumn{2}{|c|}{ CI $95 \%^{b}$} \\
\hline & & & & & & & $\begin{array}{l}\text { Lower } \\
\text { Bound }\end{array}$ & $\begin{array}{l}\text { Upper } \\
\text { Bound }\end{array}$ \\
\hline \multirow[t]{6}{*}{ Women } & TT (284) & 84.0 & $\mathrm{TM}$ & -1.1 & 1.2 & 1.000 & -4.0 & 1.8 \\
\hline & & & MM & -7.3 & 2.3 & 0.005 & -12.7 & -1.8 \\
\hline & $\mathrm{TM}(126)$ & 85.1 & TT & 1.1 & 1.2 & 1.000 & -1.8 & 4.0 \\
\hline & & & MM & -6.2 & 2.4 & 0.031 & -11.9 & -0.4 \\
\hline & MM (27) & 91.3 & TT & 7.3 & 2.3 & 0.005 & 1.8 & 12.7 \\
\hline & & & TM & 6.2 & 2.4 & 0.031 & 0.4 & 11.9 \\
\hline \multirow[t]{6}{*}{ Men } & TT (292) & 93.2 & $\mathrm{TM}$ & -3.5 & 1.3 & 0.029 & -6.8 & -0.3 \\
\hline & & & MM & -1.7 & 2.4 & 1.000 & -7.5 & 4.0 \\
\hline & $\mathrm{TM}(97)$ & 96.7 & TT & 3.5 & 1.3 & 0.029 & 0.3 & 6.8 \\
\hline & & & MM & 1.8 & 2.6 & 1.000 & -4.4 & 8.0 \\
\hline & MM (25) & 94.9 & TT & 1.7 & 2.4 & 1.000 & -4.0 & 7.5 \\
\hline & & & TM & -1.8 & 2.6 & 1.000 & -8.0 & 4.4 \\
\hline
\end{tabular}

${ }^{\mathrm{a}} P$ value: $<0.05$

${ }^{\mathrm{b}} \mathrm{CI}$ : Confidence Interval

Number of subjects contributing to the statistics is variable due to missing data for some subphenotypes used in the test. 


\section{CHAPITRE 6}

\section{DISCUSSION}

La présente étude a permis de démontrer pour la première fois une association entre l'obésité et $C X 3 C R 1$, un gène pour lequel la littérature scientifique indique un rôle dans le processus inflammatoire. Cependant, avant d'amorcer des études fonctionnelles sur ce gène, il reste plusieurs étapes méthodologiques à réaliser. Ainsi, la validation de l'association dans une autre population doit être effectuée. De plus, la séquence devrait être faite pour une quarantaine de sujets non-apparentés afin de s'assurer que les variants étudiés sont les mutations d'intérêt ${ }^{43}$. Cette étape permettrait également de définir la structure moléculaire du gène $C X 3 C R 1$. Ainsi, beaucoup de travail reste à faire pour préciser le rôle de CX3CR1 dans l'obésité et les phénotypes reliés à cette pathologie.

L'échantillon utilisé dans cette étude était composé de sujets qui étaient tous originaires du Saguenay-Lac-Saint-Jean (SLSJ), information validée par le fichier BALSAC ${ }^{185}$. La population du Saguenay-Lac-Saint-Jean s'est formée suite à trois effets fondateurs, ce qui explique le fait que la fréquence de certains allèles et par le fait même la fréquence de certaines maladies comme par exemple la tyrosinémie héréditaire de type I, l'acidose lactique, la neuropathie sensitivomotrice, l'ataxie spastique de CharlevoixSaguenay et la fibrose kystique sont plus élevées dans cette population que celles que l'on peut retrouver ailleurs dans le monde ${ }^{186}$. Pour cette même raison, d'autres maladies y sont moins fréquentes qu'ailleurs, telles la phénylcétonurie et l'hémophilie. L'hypercholestérolémie familiale est une des maladies dont la prévalence est plus élevée au SLSJ ${ }^{186}$. Cette maladie est causée par une dysfonction du récepteur de LDL-C amenant un taux de LDL-C sanguin plus élevé, et par le fait même un risque d'athérosclérose plus accru 187. Étant donné l'augmentation du taux sanguin de LDL-C, l'hypercholestérolémie 
familiale influence significativement le bilan lipidique des sujets atteints. Certains d'entre eux sont traités avec des hypolipidémiants, ce qui aurait pu avoir une influence sur certains de nos résultats. Il aurait donc été préférable de considérer cet aspect dans nos analyses. Cependant, cette information n'était pas disponible.

Bien que dans notre échantillon aucune donnée sur la présence de sujets atteints d'hypercholestérolémie familiale et la thérapie possiblement employée pour leur traitement n'était disponible, nous avons procédé à l'analyse des résultats du génotypage. Les tests effectués reposaient sur la fréquence génotypique, qui elle repose sur la fréquence allélique du polymorphisme étudié. Les populations ayant des origines différentes peuvent avoir des fréquences alléliques différentes pour un même polymorphisme ${ }^{188}$. Pour des traits fréquents, ces différences entre les populations peuvent résulter en des associations qui ne reflètent pas la relation entre le polymorphisme et le phénotype étudiés, mais qui s'expliquent plutôt par le pool génétique de la population étudiée. Il est reconnu que la population du SLSJ est caractérisée par un effet fondateur ${ }^{189}$. Ainsi, pour un polymorphisme donné, les fréquences alléliques observées peuvent être plus élevées ou plus basses que dans une autre population. Ce phénomène s'explique par le fait qu'une fraction des individus issus d'une population d'origine qui migrent vers un autre territoire porte une fraction des variants génétiques de cette population d'origine avec eux. La nouvelle population ainsi formée présentera après quelques générations une fréquence pour ces variants qui sera intimement liée aux individus ayant migrés de même qu'à leur succès de reproduction et sera différente de celle observée dans la population d'origine. Ainsi, une association observée dans une population peut ne pas être répliquée dans une autre ou ne l'être que partiellement. La réplication d'une étude d'association génétique étant une étape exigée afin d'atteindre les standards de recherche actuels ${ }^{190}$, il serait donc important de vérifier si l'association observée dans notre étude serait également présente dans d'autres échantillons provenant de populations caucasiennes différentes et par la suite dans des populations non caucasiennes. 
À l'«ère post génomique», au moment où l'approche utilisée pour la recherche en génétique des traits complexes porte quasi-essentiellement sur les études d'association pangénomiques, il est justifié de se questionner sur l'utilisation de l'approche par gène candidat dans la présente étude. Ainsi, les études d'association pangénomiques ont permis de révéler de nouveaux marqueurs impliqués dans l'obésité ${ }^{55-57,59-63}$. Toutefois, elles n'ont pas permis de détecter d'association avec des gènes codant pour des protéines impliquées dans l'inflammation, bien que cette voie biologique soit en partie documentée dans le contexte de l'obésité. Ceci illustre l'importance d'utiliser d'autres stratégies basées sur des hypothèses bien définies sur la base des connaissances biologiques (en anglais hypothesis driven) ainsi que des cohortes plus modestes, mais présentant un phénotype bien caractérisé. Dans notre étude, le choix d'adopter une approche par gène candidat a ainsi permis de détecter une association entre l'obésité et le gène $C X 3 C R I$.

Basée sur les différents travaux en cours sur la génétique des traits complexes, l'approche méthodologique multiple ou intégrée est à favoriser, c'est-à-dire l'intégration des données de criblage génétique, des études d'associations de gène candidat, l'emploi des outils in silico et les études d'expression. Cette approche devrait mener à l'identification de gènes et de voies biologiques (pathways) reliés à l'obésité et éventuellement au développement d'études fonctionnelles menant à une meilleure connaissance de la biologie moléculaire du trait.

Par ailleurs, l'obésité est une maladie qui fait l'objet de multiples études étant donné l'augmentation de sa prévalence dans plusieurs pays industrialisés et en développement ${ }^{1}$. Au-delà de son rôle d'emmagasinage, de protection mécanique et d'isolation thermique, la fonction sécrétrice du tissu adipeux est bien établie ${ }^{71}$. Les cellules présentes dans le tissu adipeux obèse produisent et sécrètent entre autres des facteurs impliqués dans l'inflammation ${ }^{7}$. Certains de ces facteurs comme les chimiokines sont chimiotactiques et engendrent le recrutement des monocytes périphériques vers le site d'inflammation par le biais de l'activation de récepteurs transmembranaires associés aux protéines $\mathrm{G}^{191}$. Le 
récepteur CX3CR1 fait partie de cette famille de récepteurs transmembranaires et est également le récepteur unique de son ligand, la fractalkine ${ }^{147}$.

L'obésité, probablement par le biais de l'inflammation qui lui est associée, contribue à l'augmentation et à l'exacerbation de maladies à composante inflammatoire comme les maladies cardiovasculaires, l'hypertension et le diabète. Quelques cytokines sécrétées dans le tissu adipeux comme le TNF- $\alpha$, l'IL-6 ainsi que des chimiokines comme MCP-1 ont été suggérées pour établir un lien moléculaire entre l'obésité et les maladies inflammatoires associées ${ }^{192}$. Le récepteur de la fractalkine, CX3CR1, associé à plusieurs maladies inflammatoires, telles que les maladies cardiovasculaires ${ }^{193}$ et l'hypertension ${ }^{194}$, pourrait également constituer un lien possible entre l'obésité et les maladies inflammatoires liées à celle-ci. En plus de sa fonction classique de facteur chimiotactique, l'interaction de haute affinité de la fractalkine avec son récepteur spécifique CX3CR ${ }^{147}$ influence la capture, l'adhésion ainsi que l'activation des leucocytes ${ }^{164}$ et des monocytes ${ }^{157}$. Les résultats obtenus dans notre étude suggèrent une association entre l'obésité et les polymorphismes communs du gène CX3CR1. Des études fonctionnelles sont nécessaires afin d'éclaircir le rôle du complexe CX3CL1/CX3CR1 dans le mécanisme inflammatoire observé dans l'obésité.

Cependant, il a été démontré que l'obésité est associée à une accumulation de macrophages dans le tissu adipeux ${ }^{89}$. Daoudi et al. ${ }^{170}$ ont démontré que des monocytes exprimant les allèles mineurs des polymorphismes communs de CX3CR 1 adhèrent plus fortement que les cellules exprimant les allèles sauvages. Chez les personnes obèses, il est possible que la présence des allèles mineurs de CX3CR1 engendre un recrutement de macrophages plus important, ou excessif, dans le tissu adipeux.

Bien que les processus inflammatoires dans l'obésité soit en partie documenté, que plusieurs facteurs impliqués dans ce dysfonctionnement métabolique soient identifiés, et que des liens avec les autres composantes du syndrome métabolique soient définis ${ }^{76}$, 
plusieurs travaux devront être réalisés pour préciser davantage les mécanismes inflammatoires impliqués ainsi que le rôle des divers biomarqueurs inflammatoires dans le développement et la persistance de l'obésité.

Par ailleurs, les avancées dans le domaine de la génétique ont permis de révéler des facteurs impliqués dans l'obésité ${ }^{19}$. En effet, plusieurs gènes ont été associés au développement de l'obésité et des traits qui lui sont reliés ${ }^{44}$. Ces nouvelles cibles thérapeutiques ont fait l'objet d'efforts de recherche afin de développer des médicaments pour traiter l'obésité.

Cependant, les traitements actuels, développés à partir des connaissances de la pathologie et des associations génétiques, provoquent parfois des effets secondaires à éviter chez certains patients obèses ${ }^{19}$. Une absence de réponse au traitement peut également être observée ${ }^{19}$. Il est donc impératif de continuer l'effort de recherche afin d'identifier des cibles thérapeutiques qui pourraient éventuellement aboutir au développement d'un médicament qui causerait le moins d'effets indésirables possibles chez les patients obèses (approche thérapeutique personnalisée sur la base de marqueur génétique).

Parmi les facteurs impliqués dans l'inflammation, le récepteur CX3CR 1 constitue une cible thérapeutique intéressante. En effet, à titre d'exemple, l'utilisation d'un antagoniste qui bloquerait le site de liaison de la fractalkine sur son récepteur, pourrait permettre de diminuer le recrutement de monocytes et autres cellules immunocompétentes au site d'inflammation, ce qui aurait comme résultat une réduction de l'inflammation dans le tissu.

Les résultats de cette étude suggèrent une association entre l'obésité et les polymorphismes communs T280M et V249I du gène CX3CRI. L'identification d'un facteur influant le développement de l'obésité est important, mais la compréhension de son rôle et de sa mise en contexte avec les autres facteurs impliqués dans le développement de 
l'obésité permettra d'en retirer la véritable signification étiologique. Des études fonctionnelles sont nécessaires afin d'investiguer le rôle de ces polymorphismes dans le processus inflammatoire observé dans le tissu adipeux obèse. Le récepteur CX3CR1 et son ligand, la fractalkine (CX3CL1), pourraient constituer une nouvelle voie métabolique impliquée dans le recrutement des macrophages dans le tissu adipeux favorisant le développement de l'inflammation dans un contexte d'obésité. Cette voie biologique, déjà ciblée pour le développement d'outils pharmacogénétiques afin de traiter des maladies à composantes inflammatoires ${ }^{195,196}$, pourrait donc s'avérer être une cible thérapeutique potentielle pour le traitement de l'obésité et d'autres pathologies à composantes inflammatoires. 


\section{CONCLUSION}

Ces dernières années, la compréhension de la biologie du tissu adipeux et, en particulier ses fonctions de sécrétion, s'est considérablement améliorée, et il a été démontré qu'un état inflammatoire de bas niveau pourrait jouer un rôle central dans l'obésité et le diabète type 2 liée à l'insulinorésistance et aux maladies cardiovasculaires. Le gène CX3CRl, qui est associé à plusieurs maladies inflammatoires, est un biomarqueur d'obésité dans notre échantillon. Le récepteur de la fractalkine (CX3CR1) pourrait donc être ciblé

pour le traitement de l'obésité. Cependant, des études d'associations génétiques supplémentaires sont nécessaires afin de vérifier si l'association observée dans cette étude entre le gène $C X 3 C R 1$ et l'obésité est présente dans des échantillons provenant d'autres populations. De plus, des investigations fonctionnelles doivent être conduites afin de mieux comprendre et définir le rôle du complexe CX3CL1/CX3CR1 dans le développement de la composante inflammatoire présente dans l'obésité. 


\section{RÉFÉRENCES}

1. McLellan F. Obesity rising to alarming levels around the world. Lancet 2002;359:1412.

2. Shields M. Measured obesity: overweight Canadian children and adolescents. In: Nutrition: findings from the Canadian Community Health Survey; 2005.

3. Loos RJ. Recent progress in the genetics of common obesity. Br J Clin Pharmacol 2009;68:811-29.

4. Campion J, Milagro FI, Martinez JA. Individuality and epigenetics in obesity. Obes Rev 2009;10:383-92.

5. James PT, Rigby N, Leach R. The obesity epidemic, metabolic syndrome and future prevention strategies. Eur J Cardiovasc Prev Rehabil 2004;11:3-8.

6. Liberopoulos EN, Mikhailidis DP, Elisaf MS. Diagnosis and management of the metabolic syndrome in obesity. Obes Rev 2005;6:283-96.

7. Wellen KE, Hotamisligil GS. Obesity-induced inflammatory changes in adipose tissue. J Clin Invest 2003;112:1785-8.

8. Organisation mondiale de la Santé. Obésité : prévention et prise en charge de l'épidémie mondiale. Organisation mondiale de la Santé, série de rapports techniques $\mathrm{n}^{\circ}$ 894. Genève; 2000.

9. Vague $J$. The degree of masculine differentiation of obesities: a factor determining predisposition to diabetes, atherosclerosis, gout, and uric calculous disease. Am J Clin Nutr 1956;4:20-34.

10. Executive summary of the clinical guidelines on the identification, evaluation, and treatment of overweight and obesity in adults. Arch Intern Med 1998;158:1855-67.

11. Kissebah AH, Vydelingum N, Murray R, et al. Relation of body fat distribution to metabolic complications of obesity. J Clin Endocrinol Metab 1982;54:254-60.

12. Carey VJ, Walters EE, Colditz GA, et al. Body fat distribution and risk of noninsulin-dependent diabetes mellitus in women. The Nurses' Health Study. Am J Epidemiol 1997;145:614-9.

13. Kannel WB, Cupples LA, Ramaswami R, Stokes J, 3rd, Kreger BE, Higgins M. Regional obesity and risk of cardiovascular disease; the Framingham Study. J Clin Epidemiol 1991;44:183-90.

14. Hartz AJ, Rupley DC, Jr., Kalkhoff RD, Rimm AA. Relationship of obesity to diabetes: influence of obesity level and body fat distribution. Prev Med 1983;12:351-7.

15. Abate N, Garg A, Peshock RM, Stray-Gundersen J, Grundy SM. Relationships of generalized and regional adiposity to insulin sensitivity in men. J Clin Invest 1995;96:8898.

16. Goodpaster BH, Thaete FL, Simoneau JA, Kelley DE. Subcutaneous abdominal fat and thigh muscle composition predict insulin sensitivity independently of visceral fat. Diabetes 1997;46:1579-85. 
17. Janssen I, Heymsfield SB, Allison DB, Kotler DP, Ross R. Body mass index and waist circumference independently contribute to the prediction of nonabdominal, abdominal subcutaneous, and visceral fat. Am J Clin Nutr 2002;75:683-8.

18. Carr MC. The emergence of the metabolic syndrome with menopause. J Clin Endocrinol Metab 2003;88:2404-11.

19. Das SK, Chakrabarti R. Antiobesity therapy: emerging drugs and targets. Curr Med Chem 2006;13:1429-60.

20. Nambi V, Ballantyne CM. Combination therapy with statins and omega-3 fatty acids. Am J Cardiol 2006;98:34i-8i.

21. Padwal R, Li SK, Lau DC. Long-term pharmacotherapy for overweight and obesity: a systematic review and meta-analysis of randomized controlled trials. Int $\mathbf{J}$ Obes Relat Metab Disord 2003;27:1437-46.

22. Halford JC. Pharmacotherapy for obesity. Appetite 2006;46:6-10.

23. Hutton B, Fergusson D. Changes in body weight and serum lipid profile in obese patients treated with orlistat in addition to a hypocaloric diet: a systematic review of randomized clinical trials. Am J Clin Nutr 2004;80:1461-8.

24. Van Gaal LF, Rissanen AM, Scheen AJ, Ziegler O, Rossner S. Effects of the cannabinoid-1 receptor blocker rimonabant on weight reduction and cardiovascular risk factors in overweight patients: 1-year experience from the RIO-Europe study. Lancet 2005;365:1389-97.

25. Pi-Sunyer FX, Aronne LJ, Heshmati HM, Devin J, Rosenstock J. Effect of rimonabant, a cannabinoid-1 receptor blocker, on weight and cardiometabolic risk factors in overweight or obese patients: RIO-North America: a randomized controlled trial. JAMA 2006;295:761-75.

26. Gelfand EV, Cannon CP. Rimonabant: a cannabinoid receptor type 1 blocker for management of multiple cardiometabolic risk factors. J Am Coll Cardiol 2006;47:1919-26.

27. Despres JP, Golay A, Sjostrom L. Effects of rimonabant on metabolic risk factors in overweight patients with dyslipidemia. N Engl J Med 2005;353:2121-34.

28. Bray GA, Greenway FL. Current and potential drugs for treatment of obesity. Endocr Rev 1999;20:805-75.

29. Heal DJ, Gosden J, Smith SL. Regulatory challenges for new drugs to treat obesity and comorbid metabolic disorders. Br J Clin Pharmacol 2009;68:861-74.

30. Stunkard AJ, Sorensen TI, Hanis C, et al. An adoption study of human obesity. N Engl J Med 1986;314:193-8.

31. Allison DB, Kaprio J, Korkeila M, Koskenvuo M, Neale MC, Hayakawa K. The heritability of body mass index among an international sample of monozygotic twins reared apart. Int J Obes Relat Metab Disord 1996;20:501-6.

32. Kopelman PG. Obesity as a medical problem. Nature 2000;404:635-43.

33. Allison DB, Faith MS, Nathan JS. Risch's lambda values for human obesity. Int J Obes Relat Metab Disord 1996;20:990-9.

34. Vogler GP, Sorensen TI, Stunkard AJ, Srinivasan MR, Rao DC. Influences of genes and shared family environment on adult body mass index assessed in an adoption study by a comprehensive path model. Int J Obes Relat Metab Disord 1995;19:40-5. 
35. Tambs K, Moum T, Eaves LJ, et al. Genetic and environmental contributions to the variance of body height in a sample of first and second degree relatives. Am J Phys Anthropol 1992;88:285-94.

36. Bouchard C, Perusse L, Leblanc C, Tremblay A, Theriault G. Inheritance of the amount and distribution of human body fat. Int $\mathrm{J}$ Obes 1988;12:205-15.

37. Barker DJ, Gluckman PD, Godfrey KM, Harding JE, Owens JA, Robinson JS. Fetal nutrition and cardiovascular disease in adult life. Lancet 1993;341:938-41.

38. Bouchard L, Rabasa-Lhoret R, Faraj $M$, et al. Differential epigenomic and transcriptomic responses in subcutaneous adipose tissue between low and high responders to caloric restriction. Am J Clin Nutr 2010;91:309-20.

39. Bromfield J, Messamore W, Albertini DF. Epigenetic regulation during mammalian oogenesis. Reprod Fertil Dev 2008;20:74-80.

40. Dean W, Santos F, Reik W. Epigenetic reprogramming in early mammalian development and following somatic nuclear transfer. Semin Cell Dev Biol 2003;14:93-100.

41. Bullo M, Casas-Agustench P, Amigo-Correig P, Aranceta J, Salas-Salvado J. Inflammation, obesity and comorbidities: the role of diet. Public Health Nutr 2007;10:1164-72.

42. Lauritzen L, Hansen HS, Jorgensen MH, Michaelsen KF. The essentiality of long chain $\mathrm{n}-3$ fatty acids in relation to development and function of the brain and retina. Prog Lipid Res 2001;40:1-94.

43. Tabor HK, Risch NJ, Myers RM. Candidate-gene approaches for studying complex genetic traits: practical considerations. Nat Rev Genet 2002;3:391-7.

44. Rankinen T, Zuberi A, Chagnon YC, et al. The human obesity gene map: the 2005 update. Obesity (Silver Spring) 2006;14:529-644.

45. Heid IM, Vollmert C, Hinney A, et al. Association of the 103I MC4R allele with decreased body mass in 7937 participants of two population based surveys. J Med Genet 2005;42:e21.

46. Benzinou $\mathrm{M}$, Creemers JW, Choquet $\mathrm{H}$, et al. Common nonsynonymous variants in PCSK1 confer risk of obesity. Nat Genet 2008;40:943-5.

47. Shugart YY, Chen L, Day IN, et al. Two British women studies replicated the association between the Val66Met polymorphism in the brain-derived neurotrophic factor (BDNF) and BMI. Eur J Hum Genet 2009;17:1050-5.

48. Fan ZC, Tao YX. Functional characterization and pharmacological rescue of melanocortin-4 receptor mutations identified from obese patients. J Cell Mol Med 2009;13:3268-82.

49. Raposinho PD, White RB, Aubert ML. The melanocortin agonist Melanotan-II reduces the orexigenic and adipogenic effects of neuropeptide Y (NPY) but does not affect the NPY-driven suppressive effects on the gonadotropic and somatotropic axes in the male rat. J Neuroendocrinol 2003;15:173-81.

50. Fan W, Boston BA, Kesterson RA, Hruby VJ, Cone RD. Role of melanocortinergic neurons in feeding and the agouti obesity syndrome. Nature 1997;385:165-8.

51. Jackson RS, Creemers JW, Ohagi S, et al. Obesity and impaired prohormone processing associated with mutations in the human prohormone convertase 1 gene. Nat Genet 1997;16:303-6. 
52. Farooqi IS, Volders K, Stanhope R, et al. Hyperphagia and early-onset obesity due to a novel homozygous missense mutation in prohormone convertase 1/3. J Clin Endocrinol Metab 2007;92:3369-73.

53. Rios M, Fan G, Fekete C, et al. Conditional deletion of brain-derived neurotrophic factor in the postnatal brain leads to obesity and hyperactivity. Mol Endocrinol $2001 ; 15: 1748-57$.

54. Kernie SG, Liebl DJ, Parada LF. BDNF regulates eating behavior and locomotor activity in mice. EMBO J 2000;19:1290-300.

55. Scuteri A, Sanna S, Chen WM, et al. Genome-wide association scan shows genetic variants in the FTO gene are associated with obesity-related traits. PLoS Genet 2007;3:e115.

56. Dina C, Meyre D, Gallina S, et al. Variation in FTO contributes to childhood obesity and severe adult obesity. Nat Genet 2007;39:724-6.

57. Frayling TM, Timpson NJ, Weedon MN, et al. A common variant in the FTO gene is associated with body mass index and predisposes to childhood and adult obesity. Science 2007;316:889-94.

58. Norris JM, Langefeld CD, Talbert ME, et al. Genome-wide association study and follow-up analysis of adiposity traits in Hispanic Americans: the IRAS Family Study. Obesity (Silver Spring) 2009;17:1932-41.

59. Lindgren CM, Heid IM, Randall JC, et al. Genome-wide association scan metaanalysis identifies three Loci influencing adiposity and fat distribution. PLoS Genet 2009;5:e1000508.

60. Liu YJ, Liu XG, Wang $\mathrm{L}$, et al. Genome-wide association scans identified CTNNBL1 as a novel gene for obesity. Hum Mol Genet 2008;17:1803-13.

61. Meyre D, Delplanque J, Chevre JC, et al. Genome-wide association study for earlyonset and morbid adult obesity identifies three new risk loci in European populations. Nat Genet 2009;41:157-9.

62. Thorleifsson G, Walters GB, Gudbjartsson DF, et al. Genome-wide association yields new sequence variants at seven loci that associate with measures of obesity. Nat Genet 2009;41:18-24.

63. Willer CJ, Speliotes EK, Loos RJ, et al. Six new loci associated with body mass index highlight a neuronal influence on body weight regulation. Nat Genet 2009;41:25-34.

64. Yagil Y, Yagil C. Integration--a key to success in the genetic dissection of complex diseases? Trends Cardiovasc Med 2006;16:35-8.

65. Bouchard L, Tchernof A, Deshaies Y, et al. ZFP36: a promising candidate gene for obesity-related metabolic complications identified by converging genomics. Obes Surg 2007; 17:372-82.

66. Lau DC, Dhillon B, Yan H, Szmitko PE, Verma S. Adipokines: molecular links between obesity and atheroslcerosis. Am J Physiol Heart Circ Physiol 2005;288:H2031-41.

67. Hotamisligil GS, Shargill NS, Spiegelman BM. Adipose expression of tumor necrosis factor-alpha: direct role in obesity-linked insulin resistance. Science 1993;259:8791.

68. Zhang Y, Proenca R, Maffei M, Barone M, Leopold L, Friedman JM. Positional cloning of the mouse obese gene and its human homologue. Nature 1994;372:425-32. 
69. Min HY, Spiegelman BM. Adipsin, the adipocyte serine protease: gene structure and control of expression by tumor necrosis factor. Nucleic Acids Res 1986;14:8879-92.

70. Trayhurn P, Wood IS. Adipokines: inflammation and the pleiotropic role of white adipose tissue. Br J Nutr 2004;92:347-55.

71. Trayhurn P, Beattie JH. Physiological role of adipose tissue: white adipose tissue as an endocrine and secretory organ. Proc Nutr Soc 2001;60:329-39.

72. Rosen ED, Spiegelman BM. Adipocytes as regulators of energy balance and glucose homeostasis. Nature 2006;444:847-53.

73. Rajala MW, Scherer PE. Minireview: The adipocyte--at the crossroads of energy homeostasis, inflammation, and atherosclerosis. Endocrinology 2003;144:3765-73.

74. Kershaw EE, Flier JS. Adipose tissue as an endocrine organ. J Clin Endocrinol Metab 2004;89:2548-56.

75. Wellen KE, Hotamisligil GS. Inflammation, stress, and diabetes. J Clin Invest 2005;115:1111-9.

76. Hotamisligil GS. Inflammation and metabolic disorders. Nature 2006;444:860-7.

77. Cinti S. Adipocyte differentiation and transdifferentiation: plasticity of the adipose organ. J Endocrinol Invest 2002;25:823-35.

78. Cinti S. The adipose organ: morphological perspectives of adipose tissues. Proc Nutr Soc 2001;60:319-28.

79. Penicaud L, Cousin B, Leloup C, Lorsignol A, Casteilla L. The autonomic nervous system, adipose tissue plasticity, and energy balance. Nutrition 2000;16:903-8.

80. Guilherme A, Virbasius JV, Puri V, Czech MP. Adipocyte dysfunctions linking obesity to insulin resistance and type 2 diabetes. Nat Rev Mol Cell Biol 2008;9:367-77.

81. Coppack SW, Chinkes DL, Miles JM, Patterson BW, Klein S. A multicompartmental model of in vivo adipose tissue glycerol kinetics and capillary permeability in lean and obese humans. Diabetes 2005;54:1934-41.

82. Coppack SW. Adipose tissue changes in obesity. Biochem Soc Trans 2005;33:1049-

52.

83. Jernas M, Palming J, Sjoholm K, et al. Separation of human adipocytes by size: hypertrophic fat cells display distinct gene expression. FASEB J 2006;20:1540-2.

84. Skurk T, Alberti-Huber C, Herder C, Hauner H. Relationship between adipocyte size and adipokine expression and secretion. J Clin Endocrinol Metab 2007;92:1023-33.

85. Bourlier V, Zakaroff-Girard A, Miranville A, et al. Remodeling phenotype of human subcutaneous adipose tissue macrophages. Circulation 2008;117:806-15.

86. Faust IM, Johnson PR, Stern JS, Hirsch J. Diet-induced adipocyte number increase in adult rats: a new model of obesity. Am J Physiol 1978;235:E279-86.

87. Henegar C, Tordjman J, Achard V, et al. Adipose tissue transcriptomic signature highlights the pathological relevance of extracellular matrix in human obesity. Genome Biol 2008;9:R14.

88. Maury E, Ehala-Aleksejev K, Guiot Y, Detry R, Vandenhooft A, Brichard SM. Adipokines oversecreted by omental adipose tissue in human obesity. Am J Physiol Endocrinol Metab 2007;293:E656-65.

89. Weisberg SP, McCann D, Desai M, Rosenbaum M, Leibel RL, Ferrante AW, Jr. Obesity is associated with macrophage accumulation in adipose tissue. $J$ Clin Invest $2003 ; 112: 1796-808$. 
90. $\mathrm{Xu} \mathrm{H}$, Barnes GT, Yang Q, et al. Chronic inflammation in fat plays a crucial role in the development of obesity-related insulin resistance. J Clin Invest 2003;112:1821-30.

91. Kintscher U, Hartge M, Hess $\mathrm{K}$, et al. T-lymphocyte infiltration in visceral adipose tissue: a primary event in adipose tissue inflammation and the development of obesitymediated insulin resistance. Arterioscler Thromb Vasc Biol 2008;28:1304-10.

92. Cancello R, Henegar C, Viguerie N, et al. Reduction of macrophage infiltration and chemoattractant gene expression changes in white adipose tissue of morbidly obese subjects after surgery-induced weight loss. Diabetes 2005;54:2277-86.

93. Cancello R, Tordjman J, Poitou C, et al. Increased infiltration of macrophages in omental adipose tissue is associated with marked hepatic lesions in morbid human obesity. Diabetes 2006;55:1554-61.

94. Harman-Boehm I, Bluher M, Redel H, et al. Macrophage infiltration into omental versus subcutaneous fat across different populations: effect of regional adiposity and the comorbidities of obesity. J Clin Endocrinol Metab 2007;92:2240-7.

95. Zeyda M, Farmer D, Todoric J, et al. Human adipose tissue macrophages are of an anti-inflammatory phenotype but capable of excessive pro-inflammatory mediator production. Int J Obes (Lond) 2007;31:1420-8.

96. Lumeng CN, Bodzin JL, Saltiel AR. Obesity induces a phenotypic switch in adipose tissue macrophage polarization. J Clin Invest 2007;117:175-84.

97. Cinti S, Mitchell G, Barbatelli G, et al. Adipocyte death defines macrophage localization and function in adipose tissue of obese mice and humans. $J$ Lipid Res 2005;46:2347-55.

98. Sengenes C, Miranville A, Lolmede K, Curat CA, Bouloumie A. The role of endothelial cells in inflamed adipose tissue. J Intern Med 2007;262:415-21.

99. Ferri C, Desideri G, Valenti M, et al. Early upregulation of endothelial adhesion molecules in obese hypertensive men. Hypertension 1999;34:568-73.

100. Curat CA, Miranville A, Sengenes C, et al. From blood monocytes to adipose tissue-resident macrophages: induction of diapedesis by human mature adipocytes. Diabetes 2004;53:1285-92.

101. Nishimura S, Manabe I, Nagasaki M, et al. In vivo imaging in mice reveals local cell dynamics and inflammation in obese adipose tissue. J Clin Invest 2008;1 18:710-21.

102. Brakenhielm E, Cao R, Gao B, et al. Angiogenesis inhibitor, TNP-470, prevents diet-induced and genetic obesity in mice. Circ Res 2004;94:1579-88.

103. Rupnick MA, Panigrahy D, Zhang CY, et al. Adipose tissue mass can be regulated through the vasculature. Proc Natl Acad Sci U S A 2002;99:10730-5.

104. Cao Y. Angiogenesis modulates adipogenesis and obesity. J Clin Invest 2007;117:2362-8.

105. Shoelson SE, Lee J, Goldfine AB. Inflammation and insulin resistance. J Clin Invest 2006;116:1793-801.

106. Nomiyama T, Perez-Tilve D, Ogawa D, et al. Osteopontin mediates obesity-induced adipose tissue macrophage infiltration and insulin resistance in mice. $J$ Clin Invest 2007; 117:2877-88.

107. Goralski KB, McCarthy TC, Hanniman EA, et al. Chemerin, a novel adipokine that regulates adipogenesis and adipocyte metabolism. J Biol Chem 2007;282:28175-88. 
108. Cottam DR, Mattar SG, Barinas-Mitchell E, et al. The chronic inflammatory hypothesis for the morbidity associated with morbid obesity: implications and effects of weight loss. Obes Surg 2004;14:589-600.

109. Dandona P, Weinstock R, Thusu K, Abdel-Rahman E, Aljada A, Wadden T. Tumor necrosis factor-alpha in sera of obese patients: fall with weight loss. J Clin Endocrinol Metab 1998;83:2907-10.

110. Maury E, Noel L, Detry R, Brichard SM. In vitro hyperresponsiveness to tumor necrosis factor-alpha contributes to adipokine dysregulation in omental adipocytes of obese subjects. J Clin Endocrinol Metab 2009;94:1393-400.

111. Fain JN, Bahouth SW, Madan AK. TNFalpha release by the nonfat cells of human adipose tissue. Int J Obes Relat Metab Disord 2004;28:616-22.

112. Cawthorn WP, Sethi JK. TNF-alpha and adipocyte biology. FEBS Lett 2008;582:117-31.

113. Shoelson SE, Herrero L, Naaz A. Obesity, inflammation, and insulin resistance. Gastroenterology 2007;132:2169-80.

114. Hirosumi J, Tuncman G, Chang L, et al. A central role for JNK in obesity and insulin resistance. Nature 2002;420:333-6.

115. Kaneto H, Nakatani Y, Miyatsuka T, et al. Possible novel therapy for diabetes with cell-permeable JNK-inhibitory peptide. Nat Med 2004;10:1128-32.

116. Wang B, Trayhurn P. Acute and prolonged effects of TNF-alpha on the expression and secretion of inflammation-related adipokines by human adipocytes differentiated in culture. Pflugers Arch 2006;452:418-27.

117. Wang B, Jenkins JR, Trayhurn P. Expression and secretion of inflammation-related adipokines by human adipocytes differentiated in culture: integrated response to TNFalpha. Am J Physiol Endocrinol Metab 2005;288:E731-40.

118. Bruun JM, Lihn AS, Verdich C, et al. Regulation of adiponectin by adipose tissuederived cytokines: in vivo and in vitro investigations in humans. Am $\mathbf{J}$ Physiol Endocrinol Metab 2003;285:E527-33.

119. Ruan H, Hacohen N, Golub TR, Van Parijs L, Lodish HF. Tumor necrosis factoralpha suppresses adipocyte-specific genes and activates expression of preadipocyte genes in 3T3-L1 adipocytes: nuclear factor-kappaB activation by TNF-alpha is obligatory. Diabetes 2002;51:1319-36.

120. Bastard JP, Lagathu C, Caron M, Capeau J. Point-counterpoint: Interleukin-6 does/does not have a beneficial role in insulin sensitivity and glucose homeostasis. $\mathbf{J}$ Appl Physiol 2007;102:821-2; author reply 5.

121. Mohamed-Ali V, Goodrick S, Rawesh A, et al. Subcutaneous adipose tissue releases interleukin-6, but not tumor necrosis factor-alpha, in vivo. $J$ Clin Endocrinol Metab 1997;82:4196-200.

122. Fried SK, Bunkin DA, Greenberg AS. Omental and subcutaneous adipose tissues of obese subjects release interleukin-6: depot difference and regulation by glucocorticoid. $\mathbf{J}$ Clin Endocrinol Metab 1998;83:847-50.

123. Yudkin JS, Kumari M, Humphries SE, Mohamed-Ali V. Inflammation, obesity, stress and coronary heart disease: is interleukin-6 the link? Atherosclerosis 2000;148:20914. 
124. Fontana L, Eagon JC, Trujillo ME, Scherer PE, Klein S. Visceral fat adipokine secretion is associated with systemic inflammation in obese humans. Diabetes 2007;56:1010-3.

125. Li JJ, Fang CH. C-reactive protein is not only an inflammatory marker but also a direct cause of cardiovascular diseases. Med Hypotheses 2004;62:499-506.

126. Stith RD, Luo J. Endocrine and carbohydrate responses to interleukin-6 in vivo. Circ Shock 1994;44:210-5.

127. Nonogaki K, Fuller GM, Fuentes NL, et al. Interleukin-6 stimulates hepatic triglyceride secretion in rats. Endocrinology 1995;136:2143-9.

128. Pedersen BK, Fischer CP. Physiological roles of muscle-derived interleukin-6 in response to exercise. Curr Opin Clin Nutr Metab Care 2007;10:265-71.

129. Bruun JM, Lihn AS, Pedersen SB, Richelsen B. Monocyte chemoattractant protein1 release is higher in visceral than subcutaneous human adipose tissue (AT): implication of macrophages resident in the AT. J Clin Endocrinol Metab 2005;90:2282-9.

130. Kanda H, Tateya S, Tamori Y, et al. MCP-1 contributes to macrophage infiltration into adipose tissue, insulin resistance, and hepatic steatosis in obesity. $J$ Clin Invest 2006;116:1494-505.

131. Weisberg SP, Hunter D, Huber R, et al. CCR2 modulates inflammatory and metabolic effects of high-fat feeding. J Clin Invest 2006;116:115-24.

132. Sartipy P, Loskutoff DJ. Monocyte chemoattractant protein 1 in obesity and insulin resistance. Proc Natl Acad Sci U S A 2003;100:7265-70.

133. Simeoni E, Hoffmann MM, Winkelmann BR, et al. Association between the A2518G polymorphism in the monocyte chemoattractant protein-1 gene and insulin resistance and Type 2 diabetes mellitus. Diabetologia 2004;47:1574-80.

134. Martinovic I, Abegunewardene N, Seul M, et al. Elevated monocyte chemoattractant protein- 1 serum levels in patients at risk for coronary artery disease. Circ J 2005;69:1484-9.

135. Gu L, Okada Y, Clinton SK, et al. Absence of monocyte chemoattractant protein-1 reduces atherosclerosis in low density lipoprotein receptor-deficient mice. Mol Cell 1998;2:275-81.

136. Yamauchi T, Kamon J, Minokoshi Y, et al. Adiponectin stimulates glucose utilization and fatty-acid oxidation by activating AMP-activated protein kinase. Nat Med 2002;8:1288-95.

137. Ryden M, Arvidsson E, Blomqvist L, Perbeck L, Dicker A, Arner P. Targets for TNF-alpha-induced lipolysis in human adipocytes. Biochem Biophys Res Commun 2004;318:168-75.

138. Torti FM, Torti SV, Larrick JW, Ringold GM. Modulation of adipocyte differentiation by tumor necrosis factor and transforming growth factor beta. J Cell Biol 1989;108:1105-13.

139. Matsuki T, Horai R, Sudo K, Iwakura Y. IL-1 plays an important role in lipid metabolism by regulating insulin levels under physiological conditions. J Exp Med 2003;198:877-88.

140. Beutler BA, Cerami A. Recombinant interleukin 1 suppresses lipoprotein lipase activity in 3T3-L1 cells. J Immunol 1985;135:3969-71. 
141. Mocellin S, Panelli MC, Wang E, Nagorsen D, Marincola FM. The dual role of IL10. Trends Immunol 2003;24:36-43.

142. Zlotnik A, Yoshie O. Chemokines: a new classification system and their role in immunity. Immunity 2000;12:121-7.

143. Baggiolini M. Chemokines in pathology and medicine. J Intern Med 2001;250:91104.

144. Hatori K, Nagai A, Heisel R, Ryu JK, Kim SU. Fractalkine and fractalkine receptors in human neurons and glial cells. J Neurosci Res 2002;69:418-26.

145. Maciejewski-Lenoir D, Chen S, Feng L, Maki R, Bacon KB. Characterization of fractalkine in rat brain cells: migratory and activation signals for CX3CR-1-expressing microglia. J Immunol 1999;163:1628-35.

146. Bazan JF, Bacon KB, Hardiman G, et al. A new class of membrane-bound chemokine with a CX3C motif. Nature 1997;385:640-4.

147. Imai $\mathrm{T}$, Hieshima $\mathrm{K}$, Haskell $\mathrm{C}$, et al. Identification and molecular characterization of fractalkine receptor CX3CR1, which mediates both leukocyte migration and adhesion. Cell 1997;91:521-30.

148. Nakayama T, Watanabe $\mathrm{Y}$, Oiso N, et al. Eotaxin-3/CC chemokine ligand 26 is a functional ligand for CX3CR1. J Immunol 2010;185:6472-9.

149. Mionnet C, Buatois V, Kanda A, et al. CX3CR1 is required for airway inflammation by promoting $\mathrm{T}$ helper cell survival and maintenance in inflamed lung. Nat Med 2010;16:1305-12.

150. Komiya A, Nagase H, Yamada H, et al. Concerted expression of eotaxin-1, eotaxin2, and eotaxin-3 in human bronchial epithelial cells. Cell Immunol 2003;225:91-100.

151. Shinkai A, Yoshisue H, Koike M, et al. A novel human CC chemokine, eotaxin-3, which is expressed in IL-4-stimulated vascular endothelial cells, exhibits potent activity toward eosinophils. J Immunol 1999;163:1602-10.

152. Kitaura M, Suzuki N, Imai T, et al. Molecular cloning of a novel human CC chemokine (Eotaxin-3) that is a functional ligand of CC chemokine receptor 3. J Biol Chem 1999;274:27975-80.

153. Hillier LW, Fulton RS, Fulton LA, et al. The DNA sequence of human chromosome 7. Nature 2003;424:157-64.

154. Harrison JK, Barber CM, Lynch KR. cDNA cloning of a G-protein-coupled receptor expressed in rat spinal cord and brain related to chemokine receptors. Neurosci Lett 1994;169:85-9.

155. Combadiere C, Ahuja SK, Murphy PM. Cloning, chromosomal localization, and RNA expression of a human beta chemokine receptor-like gene. DNA Cell Biol 1995; 14:673-80.

156. Fong AM, Alam SM, Imai T, Haribabu B, Patel DD. CX3CR1 tyrosine sulfation enhances fractalkine-induced cell adhesion. J Biol Chem 2002;277:19418-23.

157. Ancuta $\mathrm{P}$, Rao R, Moses A, et al. Fractalkine preferentially mediates arrest and migration of CD16+ monocytes. J Exp Med 2003;197:1701-7.

158. Papadopoulos EJ, Fitzhugh DJ, Tkaczyk C, et al. Mast cells migrate, but do not degranulate, in response to fractalkine, a membrane-bound chemokine expressed constitutively in diverse cells of the skin. Eur J Immunol 2000;30:2355-61. 
159. Campbell JJ, Qin S, Unutmaz D, et al. Unique subpopulations of CD56+ NK and NK-T peripheral blood lymphocytes identified by chemokine receptor expression repertoire. J Immunol 2001;166:6477-82.

160. Haskell CA, Cleary MD, Charo IF. Unique role of the chemokine domain of fractalkine in cell capture. Kinetics of receptor dissociation correlate with cell adhesion. $J$ Biol Chem 2000;275:34183-9.

161. Schafer A, Schulz C, Eigenthaler M, et al. Novel role of the membrane-bound chemokine fractalkine in platelet activation and adhesion. Blood 2004;103:407-12.

162. Mizuno T, Kawanokuchi J, Numata K, Suzumura A. Production and neuroprotective functions of fractalkine in the central nervous system. Brain Res 2003;979:65-70.

163. Bjerkeli V, Damas JK, Fevang B, Holter JC, Aukrust P, Froland SS. Increased expression of fractalkine (CX3CL1) and its receptor, CX3CR1, in Wegener's granulomatosis--possible role in vascular inflammation. Rheumatology (Oxford) 2007;46:1422-7.

164. Fong AM, Robinson LA, Steeber DA, et al. Fractalkine and CX3CR1 mediate a novel mechanism of leukocyte capture, firm adhesion, and activation under physiologic flow. J Exp Med 1998;188:1413-9.

165. Lesnik P, Haskell CA, Charo IF. Decreased atherosclerosis in CX3CR1-/- mice reveals a role for fractalkine in atherogenesis. J Clin Invest 2003;111:333-40.

166. Tremblay K, Lemire M, Provost V, et al. Association study between the CX3CR1 gene and asthma. Genes Immun 2006;7:632-9.

167. McDermott DH, Fong AM, Yang Q, et al. Chemokine receptor mutant CX3CR1M280 has impaired adhesive function and correlates with protection from cardiovascular disease in humans. J Clin Invest 2003;111:1241-50.

168. McDermott DH, Halcox JP, Schenke WH, et al. Association between polymorphism in the chemokine receptor CX3CR1 and coronary vascular endothelial dysfunction and atherosclerosis. Circ Res 2001;89:401-7.

169. Moatti D, Faure S, Fumeron F, et al. Polymorphism in the fractalkine receptor CX3CR1 as a genetic risk factor for coronary artery disease. Blood 2001;97:1925-8.

170. Daoudi M, Lavergne E, Garin A, et al. Enhanced adhesive capacities of the naturally occurring Ile249-Met280 variant of the chemokine receptor CX3CR1. J Biol Chem 2004;279:19649-57.

171. Ghilardi G, Biondi ML, Turri O, Guagnellini E, Scorza R. Internal carotid artery occlusive disease and polymorphisms of fractalkine receptor CX3CR1: a genetic risk factor. Stroke 2004;35:1276-9.

172. Hattori H, Ito D, Tanahashi N, et al. T280M and V249I polymorphisms of fractalkine receptor CX3CR1 and ischemic cerebrovascular disease. Neurosci Lett 2005;374:132-5.

173. Lavergne E, Labreuche J, Daoudi M, et al. Adverse associations between CX3CR1 polymorphisms and risk of cardiovascular or cerebrovascular disease. Arterioscler Thromb Vasc Biol 2005;25:847-53.

174. Gugl A, Renner W, Seinost G, et al. Two polymorphisms in the fracalkine receptor CX3CR1 are not associated with peripheral arterial disease. Atherosclerosis 2003;166:33943. 
175. Norata GD, Garlaschelli K, Ongari M, Raselli S, Grigore L, Catapano AL. Effects of fractalkine receptor variants on common carotid artery intima-media thickness. Stroke 2006;37:1558-61.

176. Niessner A, Marculescu R, Haschemi A, et al. Opposite effects of CX3CR1 receptor polymorphisms V249I and T280M on the development of acute coronary syndrome. A possible implication of fractalkine in inflammatory activation. Thromb Haemost 2005;93:949-54.

177. Depner M, Kormann MS, Klopp N, et al. CX3CR1 polymorphisms are associated with atopy but not asthma in German children. Int Arch Allergy Immunol 2007;144:91-4.

178. Chelbi H, Ghadiri A, Lacheb J, et al. A polymorphism in the CCL2 chemokine gene is associated with asthma risk: a case-control and a family study in Tunisia. Genes Immun 2008;9:575-81.

179. Teupser D, Pavlides S, Tan M, Gutierrez-Ramos JC, Kolbeck R, Breslow JL. Major reduction of atherosclerosis in fractalkine (CX3CL1)-deficient mice is at the brachiocephalic artery, not the aortic root. Proc Natl Acad Sci U S A 2004;101:17795-800.

180. Yang XP, Mattagajasingh $\mathrm{S}, \mathrm{Su} \mathrm{S}$, et al. Fractalkine upregulates intercellular adhesion molecule-1 in endothelial cells through CX3CR1 and the Jak Stat5 pathway. Circ Res 2007;101:1001-8.

181. Schafer A, Schulz C, Fraccarollo D, et al. The CX3C chemokine fractalkine induces vascular dysfunction by generation of superoxide anions. Arterioscler Thromb Vasc Biol 2007;27:55-62.

182. Combadiere C, Potteaux S, Gao JL, et al. Decreased atherosclerotic lesion formation in CX3CR1/apolipoprotein E double knockout mice. Circulation 2003;107:1009-16.

183. Saederup N, Chan L, Lira SA, Charo IF. Fractalkine deficiency markedly reduces macrophage accumulation and atherosclerotic lesion formation in CCR2-/- mice: evidence for independent chemokine functions in atherogenesis. Circulation 2008;117:1642-8.

184. Combadiere C, Potteaux S, Rodero M, et al. Combined inhibition of CCL2, CX3CR1, and CCR5 abrogates Ly6C(hi) and Ly6C(lo) monocytosis and almost abolishes atherosclerosis in hypercholesterolemic mice. Circulation 2008;117:1649-57.

185. Bouchard G, Roy R, Casgrain B, Hubert M. [Population files and database management: the BALSAC database and the INGRES/INGRID system]. Hist Mes 1989;4:39-57.

186. Corporation de recherche et d'action sur les maladies héréditaires. CORAMH, 2010. (Accessed 2010, at http://www.coramh.org/.)

187. Brown MS, Goldstein JL. A receptor-mediated pathway for cholesterol homeostasis. Science 1986;232:34-47.

188. Cardon LR, Palmer LJ. Population stratification and spurious allelic association. Lancet 2003;361:598-604.

189. Heyer E, Tremblay M. Variability of the genetic contribution of Quebec population founders associated to some deleterious genes. Am J Hum Genet 1995;56:970-8.

190. Chanock SJ, Manolio T, Boehnke M, et al. Replicating genotype-phenotype associations. Nature 2007;447:655-60.

191. Luster AD. Chemokines--chemotactic cytokines that mediate inflammation. N Engl J Med 1998;338:436-45. 
192. Antuna-Puente B, Feve B, Fellahi S, Bastard JP. Adipokines: the missing link between insulin resistance and obesity. Diabetes Metab 2008;34:2-11.

193. Wong BW, Wong D, McManus BM. Characterization of fractalkine (CX3CL1) and CX3CR1 in human coronary arteries with native atherosclerosis, diabetes mellitus, and transplant vascular disease. Cardiovasc Pathol 2002;11:332-8.

194. Timofeeva AV, Goryunova LE, Khaspekov GL, et al. Altered gene expression pattern in peripheral blood leukocytes from patients with arterial hypertension. Ann $\mathrm{N} \mathrm{Y}$ Acad Sci 2006;1091:319-35.

195. D'Haese JG, Demir IE, Friess H, Ceyhan GO. Fractalkine/CX3CR1: why a single chemokine-receptor duo bears a major and unique therapeutic potential. Expert Opin Ther Targets 2010;14:207-19.

196. Dorgham K, Ghadiri A, Hermand P, et al. An engineered CX3CR1 antagonist endowed with anti-inflammatory activity. J Leukoc Biol 2009;86:903-11. 
